\title{
Mitochondrial Uncoupling Protein 2 Knock-out Promotes Mitophagy to Decrease Retinal Ganglion Cell Death in a Mouse Model of Glaucoma
}

\author{
-Daniel T. Hass and Colin J. Barnstable \\ Department of Neural and Behavioral Sciences, Pennsylvania State College of Medicine, Hershey, Pennsylvania 17033
}

\begin{abstract}
Glaucoma is a neurodegenerative disorder characterized by mitochondrial dysfunction and an increase in oxidative damage, leading to retinal ganglion cell (RGC) death. The oxidative status of RGCs is regulated intrinsically and also extrinsically by retinal glia. The mitochondrial uncoupling protein 2 (UCP2) relieves oxidative and neuronal damage in a variety of neurodegenerative disease models. We hypothesized that deletion of $U c p 2$ in either RGCs or retinal glia would increase retinal damage and RGC death in a mouse model of glaucoma. Paradoxically, we found the reverse, and deletion of mitochondrial $U c p 2$ decreased oxidative protein modification and reduced RGC death in male and female mice. This paradox was resolved after finding that $U c p 2$ deletion also increased levels of mitophagy in cell culture and retinal tissue. Our data suggest that $U c p 2$ deletion facilitates increased mitochondrial function by improving quality control. An increase in mitochondrial function explains the resistance of $U c p 2$-deleted retinas to glaucoma and may provide a therapeutic avenue for other chronic neurodegenerative conditions.
\end{abstract}

Key words: glaucoma; mitochondria; mitophagy; oxidative stress; retina; uncoupling protein

\section{Significance Statement}

Many unsolved neurodegenerative conditions result from defects in mitochondrial function. Molecular tools that can manipulate mitochondria will therefore be central to developing neuroprotective therapies. Among the most potent regulators of mitochondrial function are the uncoupling proteins, particularly UCP2. In this manuscript, we show that, while loss of Ucp2 does increase mitochondrial membrane potential and the production of reactive oxygen species, it also initiates an increase in mitophagy that is ultimately neuroprotective. This novel protective consequence of uncoupling protein inhibition may lead to new therapeutic approaches to combat neurodegenerative disease, particularly because pharmacological compounds do exist that can selectively inhibit UCP2.

\section{Introduction}

Glaucoma is a group of disorders marked by progressive degeneration and death of retinal ganglion cells (RGCs) that leads to irreversible visual decline. Globally, glaucoma is the most frequent cause of irreversible blindness (Resnikoff and Keys, 2012). Primary open-angle glaucoma is the most common form of the disease, and risk for primary open-angle glaucoma increases with age and elevated intraocular pressure (IOP) (Boland and Quigley,

\footnotetext{
Received Nov. 6, 2018; revised Feb. 14, 2019; accepted Feb. 15, 2019.

Author contributions: D.T.H. and C.J.B. designed research; D.T.H. performed research; D.T.H. analyzed data; D.T.H. wrote the first draft of the paper; D.T.H. and C.J.B. edited the paper; D.T.H. wrote the paper.

This work was supported by the National Institutes of Health and the Macula Vision Research Foundation. We thank Angela Snyder for providing the mouse diagram used in Figures 1 and 3; and Drs. Evgenya Popova, Gregory Yochum, and lan Simpson for critical review of, and intellectual contributions to, this manuscript.

The authors declare no competing financial interests.

Correspondence should be addressed to Colin J. Barnstable at cbarnstable@psu.edu.

https://doi.org/10.1523/JNEUROSCI.2702-18.2019

Copyright $\odot 2019$ the authors
}

2007; Tham et al., 2014). However, other signs, such as a change in retinal morphology or loss of visual function, are sufficient for a glaucoma diagnosis without an elevated IOP (Quigley, 2011).

Although glaucoma is often defined by the loss of RGCs, its pathophysiology is multifactorial and involves changes to multiple cell types within the inner retina, including Müller glia and astrocytes (Varela and Hernandez, 1997; Carter-Dawson et al., 1998; Kawasaki et al., 2000; Woldemussie et al., 2004). In models of glaucoma, the mitochondria of these cell types become dysfunctional (Lee et al., 2011; Ju et al., 2015). Mitochondrial dysfunction can result in a bioenergetic deficit or increased levels of damaging ROS in the eye (Tanihara et al., 1997; Varela and Hernandez, 1997; Ferreira et al., 2010). The restoration of mitochondrial homeostasis and antioxidative support to both neurons and glia of the retina and optic nerve has become a major focus in research to prevent glaucomatous neurodegeneration (Kong et al., 2009; Lee et al., 2011; Garcia-Medina et al., 2015; Shen et al., 2015; Kimura et al., 2017). 
Mitochondrial hydrogen peroxide production is highly dependent on mitochondrial $\mathrm{pH}$ and membrane potential $\left(\Psi_{\mathrm{m}}\right)$, and small decreases in $\Psi_{\mathrm{m}}$ or $\mathrm{pH}$ cause significant decreases in the production of ROS, such as $\mathrm{H}_{2} \mathrm{O}_{2}$ (Korshunov et al., 1997; Miwa et al., 2003). The activity of exogenous agents that decrease $\Psi_{\mathrm{m}}$ cannot be easily regulated within cells, and their use would risk a complete collapse of $\Psi_{\mathrm{m}}$ and, thus, ATP production. Alternatively, it is the prototypical function of endogenous uncoupling proteins to uncouple the electron transport chain from ATP synthase activity and decrease $\Psi_{\mathrm{m}}$ (Fleury et al., 1997; Echtay et al., 2001). The transcription, translation, and activity of endogenous uncoupling proteins are each regulated by multiple factors (Donadelli et al., 2014; Lapp et al., 2014).

There are 5 members of the uncoupling protein gene family (Bouillaud et al., 2001). The mitochondrial uncoupling protein 2 gene $(U c p 2)$ is expressed in a variety of tissues, including the CNS (Pecqueur et al., 2001; Richard et al., 2001), and codes for a 309 amino acid protein (Fleury et al., 1997). UCP2 activity decreases electron transport chain efficiency, increasing energy expenditure (Zhang et al., 2001) and decreasing ROS generation (NègreSalvayre et al., 1997; Arsenijevic et al., 2000). UCP2-mediated uncoupling of mitochondria is cytoprotective under a variety of stressful conditions (Mattiasson et al., 2003; Andrews et al., 2005; Barnstable et al., 2016). As a consequence of $U c p 2$ deletion, mice generate more ROS and are increasingly susceptible to cell death following acute exposure to stressors, such as the dopaminergic neurotoxin MPTP (Andrews et al., 2005) or focal ischemia (Haines et al., 2010). Notably, Ucp2 deletion can be protective (de Bilbao et al., 2004), deleterious (Andrews et al., 2005; Haines et al., 2010), or have no clear effect on cell survival (Barnstable et al., 2016) in different models of neurodegeneration.

The goal of this study was to determine whether UCP2 normally functions to limit oxidative stress during glaucoma, thereby preventing a more severe form of the disorder. Glaucoma is a disease in which there are greater levels of ROS, and Ucp2 deletion increases the generation of ROS (Arsenijevic et al., 2000). We therefore hypothesized that deleting $U c p 2$ would increase ROS and RGC death. However, our data suggest that, by regulating mitochondrial dynamics, decreases in $U c p 2$ can reduce the accumulation of oxidative damage to the retina and decrease RGC death.

\section{Materials and Methods}

Ethical approval. This study was performed in accordance with the National Research Council's Guide for the care and use of laboratory animals (Ed 8). The protocol was approved by the Pennsylvania State University College of Medicine Institutional Animal Care and Use Committee.

Animals. WT (C57BL/6J) and transgenic mice were housed in a room with an ambient temperature of $25^{\circ} \mathrm{C}, 30 \%-70 \%$ humidity, a $12 \mathrm{~h}$ light/ dark cycle, and ad libitum access to rodent chow. Transgenic mouse strains, B6;129S-Ucp $2^{\text {tm2.1Lowl }} / \mathrm{J}$ (Ucp $2^{f l f l \text {, }}$ stock \#022394), B6.Cg-Tg(GFAP-cre/ER $\left.{ }^{T 2}\right) 505 \mathrm{Fmv} / \mathrm{J}$ (GFAP-creER ${ }^{T 2}$, stock \#012849) (Ganat et al., 2006), and $\operatorname{Tg}$ (Thy1-cre/ER ${ }^{T 2}$,-EYFP)HGfng/PyngJ (Thy1-creER ${ }^{T 2}$, stock \#012708) (Young et al., 2008), were each generated on a C57BL/6J background and purchased from The Jackson Laboratory. Ucp $2^{f l f l}$ mice contain LoxP sites flanking exons 3 and 4 of the Ucp2 gene. GFAP$c r e E R^{T 2}$ and Thy1-creER ${ }^{T 2}$ mice express a fusion product of $c r e$ recombinase and an estrogen receptor regulatory subunit $\left(c r e E R^{T 2}\right)$ under the control of the $h G F A P$ or Thyl promoters. CreER ${ }^{\mathrm{T} 2}$ activity is regulated by the estrogen receptor modulator and tamoxifen metabolite 4hydroxytamoxifen (Zhang et al., 1996); and in our studies, cre-mediated recombination of exons 3 and 4 of $U c p 2$ was promoted in 1- to 2-monthold mice by daily intraperitoneal injections of $100 \mathrm{mg} / \mathrm{kg}$ tamoxifen (Sigma-Aldrich, T5648) dissolved in sunflower seed oil (Sigma-Aldrich,
S5007) for $8 \mathrm{~d}$. $U c p 2^{f l / f l}$ mice were injected with tamoxifen at the same time points as experimental subjects.

Breeding scheme. To produce mice in which $U c p 2$ is selectively deleted in Gfap- or Thy1-expressing cells, $U c p 2^{f l / f l}$ mice were crossed with GFAP$c r e E R^{T 2}$ or Thy1-creER $R^{T 2}$ mice, and $U c p 2^{f l /+} ; c r e E R^{T 2}$-positive offspring were crossed with $U c p 2^{f l / f l}$ mice. The resulting $U c p 2^{f l / f l} ; G F A P-c r e E R^{T 2}$ or $U c p 2^{f l / f l}$;Thy1-creER $R^{T 2}$ offspring were bred with $U c p 2^{f l / f l}$, and the offspring of these pairings were used in this study.

IOP measurement. IOP was measured in isoflurane-anesthetized mice using a TonoLab (Icare) rebound tonometer, both before and after injection with polystyrene microbeads. Each reported measurement per mouse per eye is the average of 18 technical replicates. Although the amount of time under anesthesia has been shown to affect IOP (Ding et al., 2011), mice were anesthetized for $<10 \mathrm{~min}$ and yielded stable mean IOP measurements, particularly in control eyes. However, the work of Ding et al., (2011) leads us to believe that our method of measurement underestimates IOP values by at least $3 \mathrm{mmHg}$, and possibly more in bead-injected eyes (Ding et al., 2011). Mice were only included in this study whether their IOP was elevated by $3 \mathrm{mmHg}$, or whether a $t$ test of their IOP over time between bead and PBS-injected eyes was statistically significant.

Genotyping. Tissue from ear punches was lysed and digested for genotyping. $U c p 2^{f / f l}$ mice were genotyped with PCR primers flanking a LoxP site on the Ucp2 gene (Table 1,Ucp $2^{\text {flox }}$ ). To determine whether CreER ${ }^{\mathrm{T} 2}$-mediated $U c p 2$ exon 3-4 excision had occurred within a subset of samples, the reverse primer was used together with a primer outside the LoxP-flanked region (Table $1, U_{c p} 2^{\Delta}$ ). PCR conditions to amplify $U c p 2^{\text {Flox }}$ or $U c p 2^{\Delta}$ were as follows: (1) $95^{\circ} \mathrm{C}$ for $3 \mathrm{~min}$, (2) $95^{\circ} \mathrm{C}$ for $1 \mathrm{~min}$, (3) $73^{\circ} \mathrm{C}$ for $1 \mathrm{~min},(4) 72^{\circ} \mathrm{C}$ for $30 \mathrm{~s}$, (5) Go to (2) for 15 cycles $\left(-1^{\circ} \mathrm{C} /\right.$ cycle), (6) $95^{\circ} \mathrm{C}$ for $1 \mathrm{~min},(7) 58^{\circ} \mathrm{C}$ for $1 \mathrm{~min},(8) 72^{\circ} \mathrm{C}$ for $30 \mathrm{~s}$, (9) Go to (6) for 20 cycles, (10) $95^{\circ} \mathrm{C}$ for $10 \mathrm{~min}$, and (11) Hold at $4^{\circ} \mathrm{C}$. Both the Thy1-CreER ${ }^{T 2}$ and GFAP-CreER ${ }^{T 2}$ genes were genotyped using primers binding to an internal region of Cre recombinase (Table 1, Cre). PCR conditions to amplify Cre were as follows: (1) $95^{\circ} \mathrm{C}$ for $3 \mathrm{~min},(2) 95^{\circ} \mathrm{C}$ for $1 \mathrm{~min},(3) 58.1^{\circ} \mathrm{C}$ for $1 \mathrm{~min},(4) 72^{\circ} \mathrm{C}$ for $30 \mathrm{~s}$, (5) Go to (2) for $29 \mathrm{cycles}$, $95^{\circ} \mathrm{C}$ for $10 \mathrm{~min}$, and (6) Hold at $4^{\circ} \mathrm{C}$ (Ganat et al., 2006).

Microbead injection. We modeled glaucoma in mice by elevating IOP. We increased IOP in 2- to 4-month-old $U c p 2^{f l / f l}, U c p 2^{f l / f l} ; G F A P$-creER $R^{T 2}$, and $U c p 2^{f l / f l} ;$ Thy1-creER $R^{T 2}$ mice of both genders similarly to the Cone et al. (2012) ' $4+1$ ' protocol (Sappington et al., 2010; Cone et al., 2012). At least $24 \mathrm{~h}$ before bead injection, we took a baseline IOP measurement to confirm that a given mouse had a "normotensive" IOP. We found that, before bead injection, IOP is very stable and can be well represented by a single prebead measurement (data not shown). We then anesthetized mice with an intraperitoneal injection of $100 \mathrm{mg} / \mathrm{kg}$ ketamine and 10 $\mathrm{mg} / \mathrm{kg}$ xylazine, and treated each eye with topical proparacaine hydrochloride $(0.5 \%)$ to further anesthetize and hydrate the cornea during injections. We then sterilized 1 and $6 \mu \mathrm{m}$ diameter polystyrene microbeads (Polysciences, catalog \#07310-15 and 07312-5) as noted by Cone et al. (2012), and estimated bead concentrations on a hemocytometer. We injected $2 \mu \mathrm{l}$ of $6 \mu \mathrm{m}\left(\right.$ at $3 \times 10^{6}$ beads $\left./ \mu \mathrm{l}\right)$ and $2 \mu \mathrm{l}$ of $1 \mu \mathrm{m}$ (at $1.5 \times 10^{7}$ beads $/ \mu \mathrm{l}$ ) microbeads through the cornea using a 50-100 $\mu \mathrm{m}$ cannula formed by a beveled glass micropipette connected by polyethylene tubing to a Hamilton syringe (Hamilton). As an internal control, the same volume of sterile $1 \times$ PBS was injected in to the contralateral eye. We measured postoperative IOP every $3 \mathrm{~d}$ for $30 \mathrm{~d}$. Following the terminal IOP measurement, mice were asphyxiated using a Euthanex SmartBox system, which automatically controls $\mathrm{CO}_{2}$ dispersion, followed by cervical dislocation. Figure $1 B$ illustrates a visual representation of this experimental design. For measurements of gene expression, protein levels, and mitochondrial function, mice were killed $3 \mathrm{~d}$ following microbead injection, as IOP is generally maximal or near-maximal at this postoperative time point.

Cytochrome-C oxidase (COX) histochemistry. In situ COX activity was assayed using a modified procedure described previously (Wong-Riley, 1979; Murphy et al., 2012). Briefly, following death, unfixed mouse eyes were harvested, immediately frozen in OCT on dry ice, and cut in to $10 \mu \mathrm{m}$ sections. Control and experimental samples were frozen and sectioned on the same slide to minimize potential slide-to-slide variability. 
Table 1. Primers used in this study

\begin{tabular}{|c|c|c|c|}
\hline Gene & Forward $\left(5^{\prime} \rightarrow 3^{\prime}\right)$ & Reverse $\left(5^{\prime} \rightarrow 3^{\prime}\right)$ & Reference $^{a}$ \\
\hline \multicolumn{4}{|c|}{ Genotyping primers, for use with genomic DNA } \\
\hline$U c p 2^{\text {Flox }}$ & ACCAGGGCTGTCTCCAAGCAGG & AGAGCTGTTCGAACACCAGGCCA & Robson-Doucette et al., 2011 \\
\hline$U c p 2^{\Delta}$ & AGAGCTGTTCGAACACCAGGCCA & TAGAGGAGGGTGGTGTTCCAGCTC & Robson-Doucette et al., 2011 \\
\hline $\mathrm{CreER}^{T 2}$ & GCAACGAGTGATGAGGTTCGCAAG & TCCGCCGCATAACCAGTGAAACAG & Ganat et al., 2006 \\
\hline \multicolumn{4}{|c|}{ RT-PCR primers, for use with CDNA } \\
\hline Ucp2 & GCTCAGAGCATGCAGGCATCG & CGTGCAATGGTCTTGTAGGCTTCG & - \\
\hline Sod2 & TGGACAAACCTGAGCCCTAAG & CCCAAAGTCACGCTTGATAGC & Masand et al., 2018 \\
\hline Tfam & AAGGATGATTCGGCTCAGG & GGCTTTGAGACCTAACTGG & Masand et al., 2018 \\
\hline CytB & AGACAAAGCCACCTTGACCCGAT & ACGATTGCTAGGGCCGCGAT & Tewari et al., 2012 \\
\hline Nfe2l2 & GTTGCCCACATTCCCAAAC & GCAAGCGACTCATGGTCATC & - \\
\hline Hmox1 & GGGTGACAGAAGAGGCTAAGACC & GGGCAGTATCTTGCACCAGG & - \\
\hline PolgA & GCAGGATGGGCAGGAACA & GCATCCGGGAGTCCTGAA & Masand et al., 2018 \\
\hline $\mathrm{C} 10 a$ & GAGGGGAGCCAGGAGCTG & GGATTGCCTTTCACGCCC & - \\
\hline Bnip3l & ATCCCACCCAAAGAGTTCCA & CCAATATAGATGCCGAGCCC & - \\
\hline Map1-Lc3b & CCACCAAGATCCCAGTGATTA & CAAGCGCCGTCTGATTATCT & - \\
\hline Pink1 & GGGCTTGCCAATCCCTTC & GACGGTCTCTTGCTGGCC & - \\
\hline Park2 & CCCATCTTGCTGGGACG & ACATTTAAAGAAAAATTCAGCTCTGGTT & - \\
\hline $\operatorname{Pgc1} \alpha$ & AGCCGTGACCACTGACAACGAG & GCTGCATGGTTCTGAGTGCTAAG & Masand et al., 2018 \\
\hline$T b p$ & ACCTTATGCTCAGGGCTTGGCC & GTCCTGTGCCGTAAGGCATCATTG & Perreten Lambert et al., 2014 \\
\hline
\end{tabular}

Uncited primers are self-designed.

Table 2. Antibodies used in this study

\begin{tabular}{lllll}
\hline Protein & Host & Dilution & Supplier & Catalog \# \\
\hline BNIP3L/NIX & Rabbit & $1: 1000$ & Cell Signaling Technology & 12396 \\
GFAP (N18) & Goat & $1: 200$ & Santa Cruz Biotechnology & sc-6171 \\
GFAP (GA5) & Mouse & $1: 500$ & Cell Signaling Technology & 3670 \\
GFAP & Rabbit & $1: 500$ & Dako & Z0334 \\
HNEJ-2 & Mouse & $1: 25$ & Abcam & ab48506 \\
LC3B (D11) & Rabbit & $1: 200$ (ICC/IHC) & Cell Signaling Technology & 3868 \\
& & $1: 500$ (WB) & & \\
RBPMS & Rabbit & $1: 500$ & EMD Millipore & ABN1362 \\
TOMM20 & Mouse & $1: 200$ & BD Biosciences & 612278 \\
TOMM20 & Rabbit & $1: 500$ & Abcam & ab78547 \\
UCP2 & Rabbit & $1: 100$ & EMD Millipore & 662047 \\
AlexaFluor-488, goat anti-rabbit & Goat & $1: 600$ & Thermo Fisher Scientific & A11008 \\
AlexaFluor-488, goat anti-mouse & Goat & $1: 600$ & Thermo Fisher Scientific & A11001 \\
AlexaFluor-594, goat anti-mouse & Goat & $1: 600$ & Thermo Fisher Scientific & A11005 \\
AlexaFluor-594, goat anti-rabbit & Goat & $1: 600$ & Thermo Fisher Scientific & A11012 \\
AlexaFluor-647, goat anti-mouse & Goat & $1: 600$ & Thermo Fisher Scientific & A32728 \\
DyLight 543, donkey anti-goat & Donkey & $1: 600$ & Vector Labs & DI-1549 \\
\hline
\end{tabular}

Slides were incubated in an assay solution containing $4 \mathrm{~mm} \mathrm{DAB}, 100 \mu \mathrm{M}$ cytochrome C (Sigma-Aldrich, catalog \#2037), and $5 \mathrm{U} / \mathrm{ml}$ catalase (Sigma-Aldrich, catalog \#E3289) for $1 \mathrm{~h}$ at $37^{\circ} \mathrm{C}$. Assay control slides were additionally exposed to $5 \mathrm{~mm} \mathrm{NaN}_{3}$, which inhibits COX activity. Slides were imaged at $20 \times$ magnification. Analysis of staining intensity was performed using the $\mathrm{H}-\mathrm{DAB}$ setting of the ImageJ color deconvolution tool and subtracting the result from background image intensity.

Histology and immunocytochemistry. Immunolabeling of sectioned retinal tissue was performed as previously described (Pinzon-Guzman et al., 2011). Briefly, whole eyes were fixed in 4\% PFA (Electron Microscopy Sciences) in $1 \times$ PBS overnight at $4^{\circ} \mathrm{C}$. The next day, eyes were divided in half with a scalpel blade. One half was frozen and sectioned, whereas the other was labeled as a whole mount. Frozen tissue was embedded in a 2:1 mixture of $20 \%$ sucrose and OCT (Electron Microscopy Sciences), cooled to $-20^{\circ} \mathrm{C}$, and cut at a $10 \mu \mathrm{m}$ thickness. Samples for each experiment were located on the same slide to control for assay variability. Before immunohistochemical labeling, we unmasked antigens in a $\mathrm{pH}$ 6.0 sodium citrate buffer. Sections were permeabilized with $0.2 \%$ Triton $\mathrm{X}-100$ in PBS, blocked with 5\% nonfat milk, and incubated in primary antibodies (Table 2) overnight at $4^{\circ} \mathrm{C}$. The following day, sections were washed and incubated in secondary antibody for $3 \mathrm{~h}$, followed by incubation in $1 \mu \mathrm{g} / \mathrm{ml}$ Hochest-33258 for $20 \mathrm{~min}$. After three washes, slides were mounted with $0.5 \% n$-propyl gallate in 1:1 glycerol/PBS. Retinal whole mounts used a similar protocol but with the following modifica- tions: antigens were not unmasked, tissue was incubated in primary antibody for $6 \mathrm{~d}$ at $4^{\circ} \mathrm{C}$ and secondary overnight at $4^{\circ} \mathrm{C}$. Labeled tissue was imaged on a Fluoview FV1000 confocal microscope (Olympus). In each experiment, acquisition parameters for a given antibody were held constant. All fluorescent labeling intensity measurements were derived using the ImageJ measurement tool. Unless otherwise specified, intensity measurements were bounded by the ganglion cell layer and the outer nuclear layer. All slides were imaged at $40 \times$ magnification, and cells were imaged at $100 \times$ magnification. We monitored mitochondrial morphology, size, and number using the MiNa V1 plugin (Valente et al., 2017). We measured colocalization between LC3B and TOMM20 using the ImageJ plugin "Coloc 2" and reporting the Manders' overlap coefficient corresponding to the TOMM20 image channel. Tissue LC3B puncta were detected using the "Find Maxima. . ." tool with a noise tolerance of 1000, which of all the methods tested best recapitulates a visual search for LC3B puncta.

$R G C$ quantification. RGC density was estimated in the ganglion cell layer of RBPMS immunolabeled retinal whole mounts (Rodriguez et al., 2014). We used RBPMS due to the high concordance between RGC soma labeling with this marker and with several other well-characterized markers, both normally (Rodriguez et al., 2014) and pathologically after optic nerve damage (Kwong et al., 2011). This concordance suggests that loss of RBPMS labeling was due to loss of RGCs and not to loss of RBPMS expression. For each retina, RBPMS ${ }^{+}$cells were counted across 3 or 4 well-separated fields, with each field measuring $317.95 \mu \mathrm{m} \times 317.95 \mu \mathrm{m}$ and centered $1000 \mu \mathrm{m}$ from the optic nerve head. This corresponds to a total area of $0.3-0.4 \mathrm{~mm}^{2}$ counted per retina. Cell counts were converted to measurements of RGC density and averaged for a single retina. The observer counting RGC numbers in these images was blinded to the identity of each sample. RGC density was calculated from cell count these images, and RGC loss was calculated as the difference in these averages between PBS-injected retinas and contralateral bead-injected retinas. Mean \pm SEM and median RGC densities were $4283 \pm 83$ and 4169 cells $/ \mathrm{mm}^{2}$, respectively, in PBS-injected $U c p 2^{\mathrm{fl} / \mathrm{fl}}$ retinas, comparable with values found in the literature for this marker (Rodriguez et al., 2014; Wang et al., 2017). The percentage of RGC death following microbead injection was also similar to our own findings using a different RGC marker, Brn3a (D.T.H. et al., unpublished observations). We did not find a significant effect of bead injection on retinal quadrant RGC density, and our images were therefore averaged from across all retinal quadrants for a given sample.

RNA isolation and qRT-PCR. Frozen tissue was lysed in TRIzol (Thermo Fisher Scientific, catalog \#15596018) and RNA precipitated using the manufacturer's recommended procedure. Final RNA concentration was measured using a NanoDrop ND-1000 Spectrophotometer 
before reverse transcription. We reverse-transcribed RNA using SuperScript III (Thermo Fisher Scientific, catalog \#18080093) with random hexamers. cDNA was amplified with iQ SYBR Green Supermix (BioRad, catalog \#1708882) and quantitated on an iCycler (Bio-Rad). All primers designed to measure gene expression (Table 1) do not amplify genomic sequences, and qPCRs were followed by a melt curve analysis to confirm the amplification of a single PCR product. All results were normalized against the TATA-box binding protein $(T b p)$ cDNA using the $\Delta \Delta \mathrm{C}_{\mathrm{t}}$ method. Tbp is stably expressed during both mouse retinal development (Adachi et al., 2015) and in retinal endothelial cells treated with innate immune system stimulants (Wei et al., 2013).

Primary astrocyte culture. Primary mouse cortical astrocytes were isolated from postnatal day 1-4 mice as previously described (Sarafian et al., 2010; Lapp et al., 2014). Briefly, mice were decapitated, and brains were removed from the skull. In tissue culture medium, an $\sim 1 \mathrm{~cm}$ portion of superior cerebral cortex was pinched off of the brain using curved forceps. Meninges were removed, and the tissue was triturated with a sterile flame-polished glass Pasteur pipette until it formed a single-cell suspension $(\sim 20 \times)$. The suspension was filtered through a $70 \mu \mathrm{m}$ cell strainer to remove larger debris, centrifuged at $500 \times g$ and $4^{\circ} \mathrm{C}$ for $5 \mathrm{~min}$, resuspended in growth medium (DMEM/Ham's F12 supplemented with 2 mM L-glutamine, $15 \mathrm{~mm}$ HEPES, $10 \% \mathrm{FBS}$, and $10 \mathrm{ng} / \mathrm{ml}$ gentamicin), and plated in a T-25 tissue culture flask. Cells were grown at $37^{\circ} \mathrm{C}$ in a $5 \% \mathrm{CO}_{2}$ /balance air atmosphere. After the cells have reached confluence between 7 and 14 DIV, contaminating cells were shaken off at 250 RPM overnight and growth medium was replaced. Astrocyteenriched cultures were then passaged at least $48 \mathrm{~h}$ following medium replacement for experimentation, and used for experimentation at passage 2 or passage 3 . All cells used in this study were exposed to $1 \mu \mathrm{M}$ 4-hydroxytamoxifen (Sigma-Aldrich, catalog \#H6278) for $24 \mathrm{~h}$ before studies of $U c p 2$ function.

Measurement of mitochondrial membrane potential and oxidative status. We determined that mitochondrial membrane potential $\left(\Psi_{\mathrm{m}}\right)$ and relative oxidative status were determined on a fluorescence-enabled microplate reader (BioTek Synergy II) using black tissue-culture-treated 96-well plates (Corning, catalog \#3603) seeded with 30,000 cells/well. We treated all primary astrocytes from $U c p 2^{f l / f l}$ and $U c p 2^{f l / f l} ; G F A P-c r e E R^{T 2}$ mice with 4 -hydroxytamoxifen and washed it out at least $24 \mathrm{~h}$ before the assay. To measure membrane potential, we loaded cells with $5,5^{\prime}, 6,6^{\prime}$ tetrachloro-1,1',3,3' -tetraethyl-benzimidazolylcarbocyanine iodide (JC-1; $2 \mu \mathrm{g} / \mathrm{ml}$; Thermo Fisher Scientific, catalog \#T3168) in culture medium for $30 \mathrm{~min}$. We measured red and green fluorescence $5 \mathrm{~min}$ after washing out each probe. Each assay contained controls treated with the membrane permeant protonophore carbonyl cyanide-4-(trifluoromethoxy) phenylhydrazone (FCCP, $1 \mu \mathrm{M}$, Cayman Chemical). We determined the effect of UCP2 on oxidant production using the redox-sensitive probe chloromethyl-2', $7^{\prime}$-di-chlorofluorescein diacetate $\left(\mathrm{CM}-\mathrm{H}_{2}-\mathrm{DCFDA}\right.$, $40 \mu \mathrm{M}$; Thermo Fisher Scientific, catalog \#C6827) in $1 \times$ PBS supplemented with $1 \mathrm{~mm}$ glucose and $2 \mathrm{~mm}$ GlutaMax (Thermo Fisher Scientific, catalog \#35050-061). The probe was washed out following a $30 \mathrm{~min}$ incubation. We measured oxidant production in the plate reader's kinetic mode, which took serial measurements of CM- $\mathrm{H}_{2}$-DCFDA fluorescence over time. The increase in fluorescence $(\Delta \mathrm{F})$ over $30 \mathrm{~min}$ was divided by initial fluorescent intensity $\left(\mathrm{F}_{0}\right)$. This rate of increase in CM$\mathrm{H}_{2}$-DCFDA fluorescence was normalized to the mean $\Delta \mathrm{F} / \mathrm{F}_{0}$ of $U c p 2^{f l f l}$ cells to minimize interassay variability.

Extracellular flux analysis. Oxygen consumption (OCR) and extracellular acidification rate were used as proxies of oxidative and glycolytic metabolism, respectively. We performed a "mitochondrial stress test" on cultured astrocytes (seeded at 30,000 cells/well) using inhibitors of electron transport at the indicated final concentrations: oligomycin $(25 \mu \mathrm{g} /$ $\mathrm{ml}$; Cayman Chemical), FCCP $(1 \mu \mathrm{M})$, antimycin A ( $1 \mu \mathrm{M})$, and rotenone $(1 \mu \mathrm{M})$. Following the assay, we measured DNA concentration in each well for normalization of OCR traces.

Western blot analysis. Western blot analysis was performed as previously described (Pinzon-Guzman et al., 2011). Briefly, dissected retinal tissue was homogenized in RIPA buffer supplemented with Halt protease inhibitor mixture (Thermo Fisher Scientific, catalog \#78430) and a phosphatase inhibitor mixture set II (EMD Millipore, catalog \#524625). Pro- tein concentration was estimated with a DC protein assay (Bio-Rad, catalog \#5000111); $20 \mu \mathrm{g}$ retinal homogenate was loaded on a $4 \%-12 \%$ Criterion TGX polyacrylamide gel (Bio-Rad, catalog \#5678124) and run at $240 \mathrm{~V}$ for $35 \mathrm{~min}$ before semidry transfer to a $0.45 \mu \mathrm{m}$ nitrocellulose membrane (Bio-Rad, catalog \#1620115) at $16 \mathrm{~V}$ for $40 \mathrm{~min}$. Leftover protein was visualized with Coomassie Blue staining, and the sum of Coomassie-labeled histone bands was used for protein normalization.

The membrane was washed in $1 \times$ TBS with $0.1 \%$ Tween 20 (TBS-T) and blocked in TBS-T with $2 \%(\mathrm{w} / \mathrm{v})$ blotting grade blocker (Bio-Rad, catalog \#1706404). Membranes were incubated in primary antibodies (Table 2) diluted in blocking buffer overnight at $4^{\circ} \mathrm{C}$. Membranes were washed in TBS-T and incubated in secondary antibody for $2 \mathrm{~h}$ at room temperature before generation of chemiluminescent bands with Pierce ECL Western Blotting Substrate (Thermo Fisher Scientific, catalog \#32106) and visualization on photosensitive films (Thermo Fisher Scientific, catalog \#34091). Band density was determined from scanned developed films using ImageJ.

Statistical analysis. We performed all statistical analyses in GraphPad Prism. Linear trends were analyzed with a linear regression. We determined the statistical effect of one independent variable on two groups used a Student's $t$ test or paired sample $t$ test in cases where samples were matched (e.g., the control was the contralateral eye of the same animal). We analyzed the effect of one variable on more than two groups using a one-way ANOVA with a Holm-Sidak post hoc analysis. We analyzed the effect of two variables using a two-way ANOVA with a Holm-Sidak post hoc analysis. The statistical significance threshold was $p<0.05$ for all tests.

\section{Results}

\section{UCP2 localization in the retina and characteristics of the} microbead model

To confirm that UCP2 is normally present in the retina and to determine its cellular localization, we immunolabeled fixed retinal tissue from WT C57BL/6J and whole-body Ucp2 KO mice (courtesy of Dr. Sabrina Diano). Retinas from Ucp2-KO mice were used as a control for antibody specificity. UCP2 protein was distributed throughout the mouse retina, with strong expression within the RGC layer (retinal ganglion cell layer) and photoreceptor inner segments (Fig. 1A, left). To study the actions of UCP2 in a mouse model of glaucoma, we implemented a microbead model that elevates IOP, illustrated in Figure $1 B$. Before further studies, we confirmed that neither gender nor genotype had an effect on the baseline IOP characteristics of the mouse eye (Fig. 1B). We also confirmed that injection of microbeads into the anterior chamber of the eye resulted in their migration to the aqueous humor outflow pathway, at the iridocorneal angle (Fig. $1 D)$. We found a significant $(p=0.0175, \mathrm{df}=12, n=14)$ but overall weak relationship $\left(R^{2}=0.39\right)$ between the bead-induced increase in IOP and a decrease in RGC survival, measured by a decrease in the density of $\mathrm{RBPMS}^{+}$RGCs in retinal whole mounts between PBS- and microbead-injected eyes (Fig. 1E).

\section{Elevated IOP decreases mitochondrial function and increases oxidative stress}

One stable mark of oxidative damage is accumulation of lipid peroxidation products, such as 4-hydroxy-2-nonenal (HNE) (Malone and Hernandez, 2007). HNE can modify histidine residues on proteins, forming a stable adduct that we used as a proxy for oxidative stress in tissue. To determine whether retinas are stressed in the microbead glaucoma model, we compared HNE labeling in the retinal layers of microbead- and PBS-injected eyes. Microbead injection significantly increased HNE reactivity in the inner retina to $159 \pm 29 \%$ of contralateral PBS-injected eyes $(p=$ $0.0035, \mathrm{df}=36, n=5)$, but not in the outer retina ( $98 \pm 23 \%$ of contralateral control). Analysis of individual inner retinal layers 
A

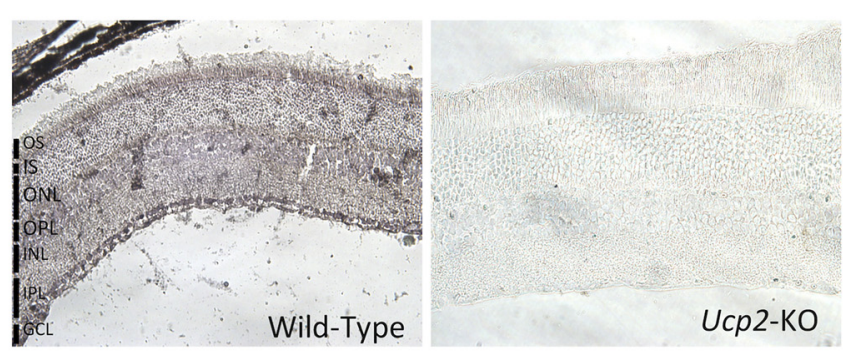

B
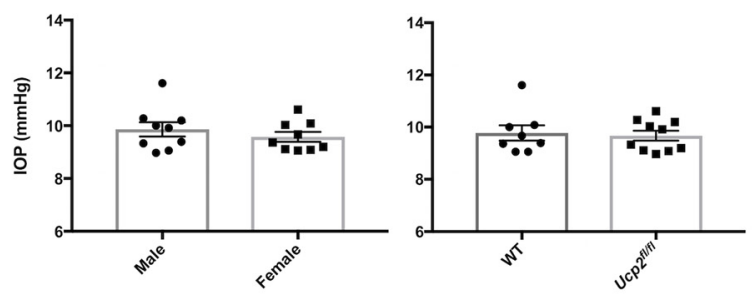

C

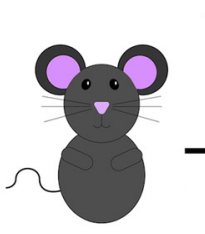

Tamoxifen Injected

(1x/day for 8d) Microbeads Injected (day 0)

Mouse euthanized

[4-HNE, GFAP, RGC]

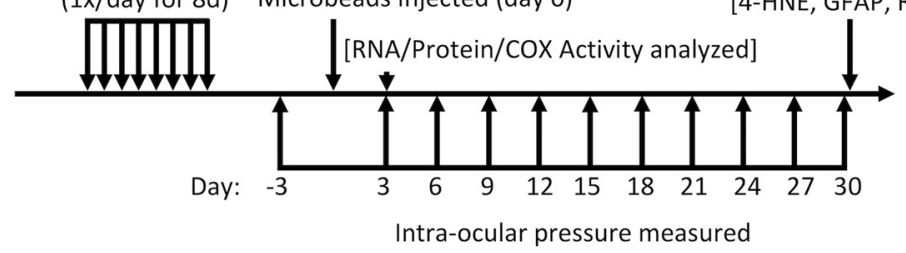

D
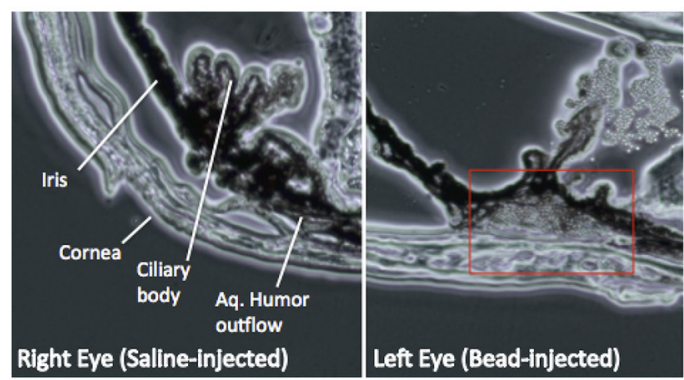

E

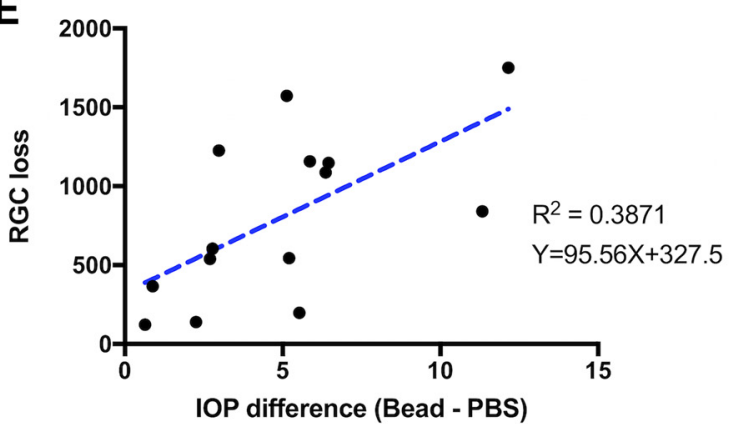

Figure 1. Expression of UCP2 in the retina and characteristics of the microbead model of glaucoma. $A$, Representative immunohistochemical labeling of UCP2 in retinas from full-body UCP2-KO mice and WT mice, showing that UCP2 is distributed throughout the retina but is expressed to a greater extent in the ganglion cell layer. $B$, Schematic diagram representing the order and timing of manipulations made to mice before and during the microbead model of glaucoma. C, Baseline (prebead injection) IOP compared between male and female C57BL/6J mice (left), showing no effect of gender on IOP. These data were pooled and compared against baseline IOP in Ucp2 ${ }^{f / f l}$ mice. In both cases, there is no statistical difference in mean IOP ( $t$ test). $\boldsymbol{D}$, We verified the location of microbeads following injection through the cornea and found them packed between the cornea and iris, at the aqueous humor outflow pathway. $E$, At $30 \mathrm{~d}$ following IOP elevation, the difference in RGC density between PBS- and bead-injected eyes of $U\left(\mathrm{CP} 2^{f / f f}\right.$ mice was analyzed as a function of average IOP difference between those eyes, showing a positive correlation between IOP elevation and RGC loss.

showed increases in HNE, but none of these reached significance following adjustment for multiple comparisons, suggesting that, although the effects of IOP on oxidative stress may occur in multiple cell types, its main effect is within the cell type that degenerates in glaucoma (Fig. 2A,B). To determine the effect of IOP elevation on mitochondrial function, we tested COX activity in fresh-frozen slices of retina from PBS- and bead-injected mice and found that, by $3 \mathrm{~d}$ after bead injection, there was a significant decrease in retinal COX activity $(p=0.0313$, $\mathrm{df}=4, n=5$; Fig. $2 C, D)$. The decrease in COX activity was associated with expression of oxidative stress and glaucoma-related genes. We measured Hmox1, Nfe2l2, Ucp2, Sod2, and C1Qa in retinas from a group of untreated (naive) mice, and from PBS-injected, and microbead-injected mice, $3 \mathrm{~d}$ following bead injection $(n=3$, $\mathrm{df}=6)$. Bead injection increased the expression of $\operatorname{Hmox} 1$ (856 \pm $294 \%, p=0.0217), N f e 2 l 2(149 \pm 14 \%, p=0.033)$, and C1Qa $(728 \pm 295 \%, p=0.048)$ relative to contralateral bead-injected retinas, and caused smaller, nonsignificant increases in Sod2 $(117 \pm 35 \%, p=0.73)$ and notably in Ucp2 as well (366 $\pm 196 \%$, $p=0.29$; Fig. $2 E$ ). In all cases where we measured gene expression, there was no notable or statistically significant difference between retinas of naive and PBS-injected mice of the same genotype. In all subsequent experiments, we used contralateral PBS-injected retinas as a control for microbead-induced IOP elevation, and consider it useful as a proxy for normal retinas.

\section{Ucp2 deletion increases mitochondrial membrane potential $\left(\Psi_{\mathrm{m}}\right)$ and oxidative stress}

To investigate the effects of $U c p 2$ deletion on cellular function, we used primary cortical astrocytes cells from $U c p 2^{f l / f l}$ and $U c p 2^{f l f l}$; $G F A P-c r e E R^{T 2}$ mice. In Figure $3 A$ (II), we show a schematic diagram of the floxed $U c p 2$, including the region excised by cre recombinase, and the PCR primers used to determine genotype or cre recombination. We also show the two different variants of cre used in this study (I) as well as (III) a schematic indicating which figures use primary cells and which used retinal tissue. In Figure $3 B$, we show a representative agarose gel from 4-hydroxytamoxifen-pretreated $U c p 2^{f l f l}$ (Fig. $3 B$, lanes 1 and 2) and $U c p 2^{f l / f l} ; G F A P$-creER $R^{T 2}$ astrocytes (lanes 3 and 4), from which we amplified a PCR product $\left(\mathrm{Ucp} 2^{\Delta}\right)$ that is only detected in cre-expressing cells, following cre-mediated Ucp 2 exon 3 and 4 excision. We determined the effect of $U c p 2$ on mitochondrial 
A
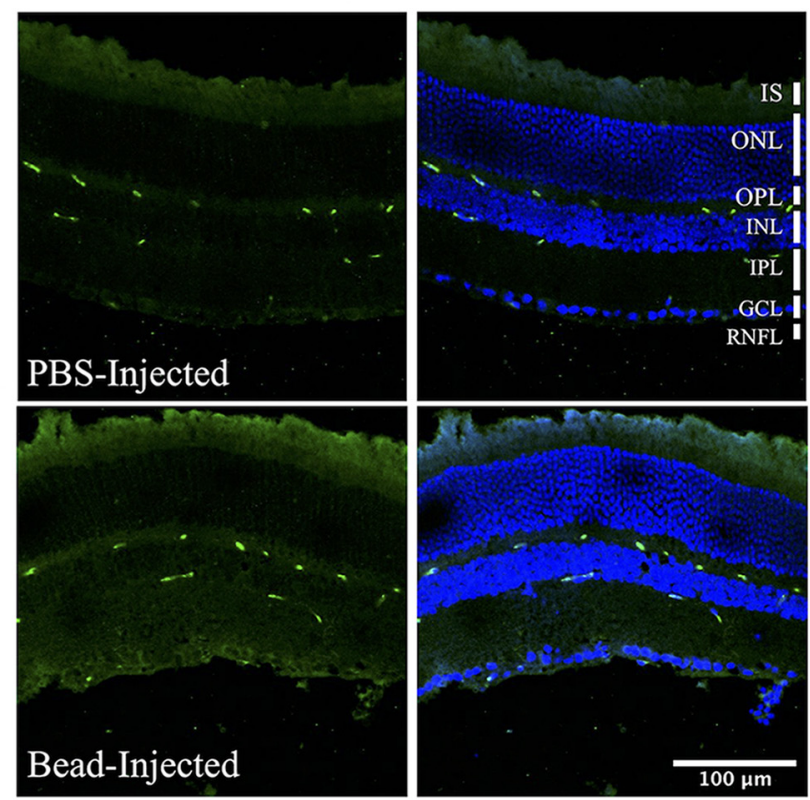

C
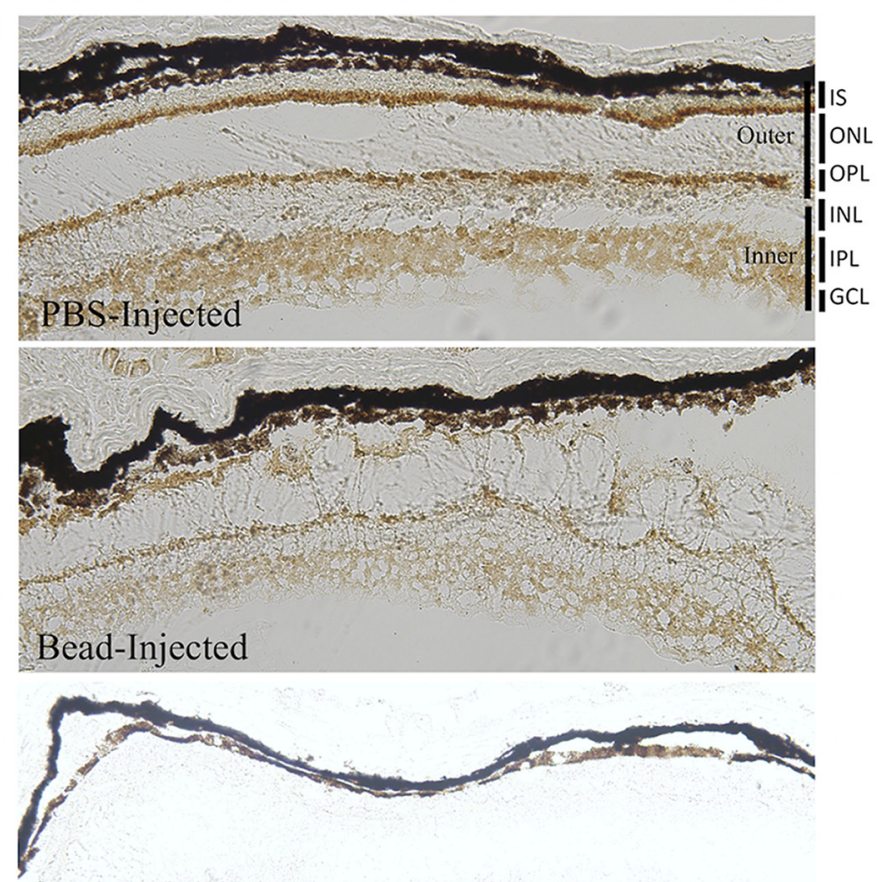

PBS-Injected $+5 \mathrm{mM} \mathrm{NaN}_{3}$
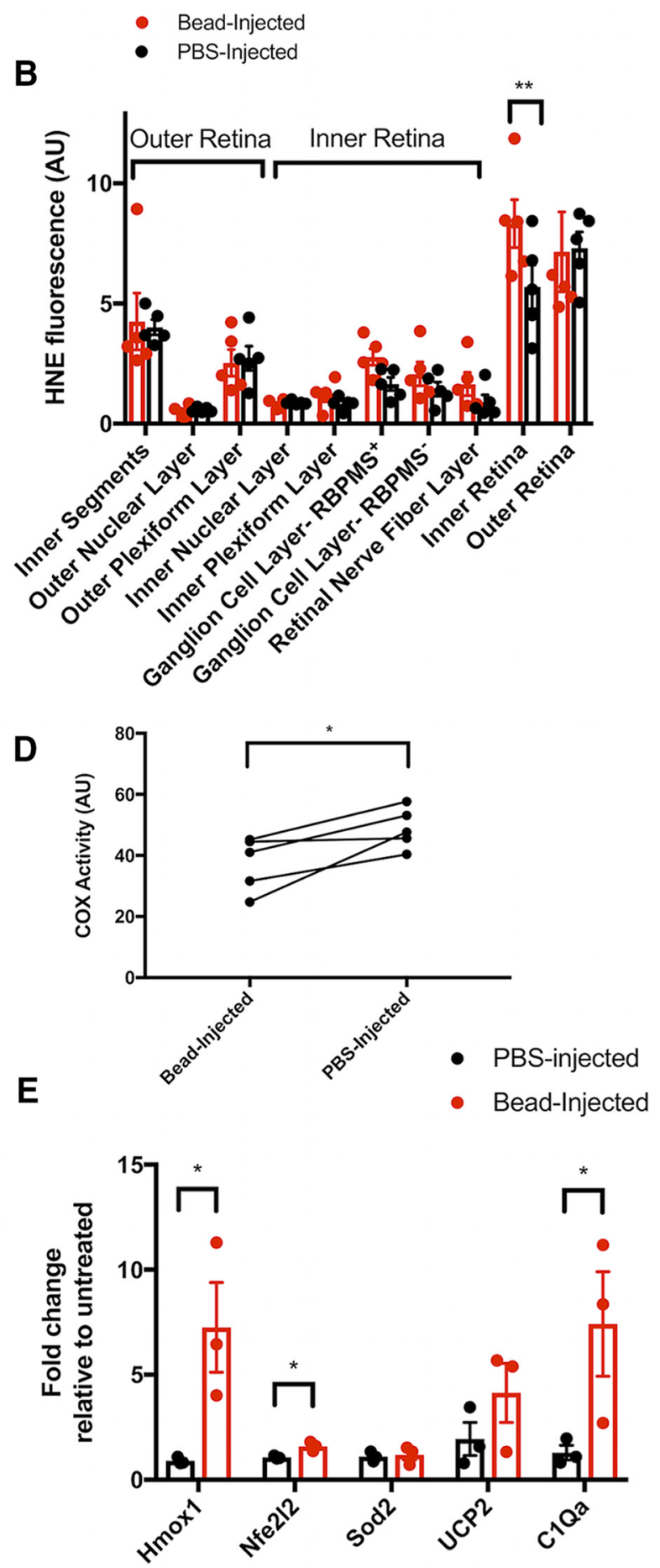

Figure 2. Elevating IOP increases oxidative stress and decreases mitochondrial function. $A$, HNE (green) and Hoechst-33258 (blue) labeling of retinal sections from PBS- and microbead-injected eyes, $30 \mathrm{~d}$ after injection. Scale bar, $100 \mu \mathrm{m}$. B, Quantification of immunoreactivity in different retinal layers reveals that HNE labeling is significantly greater within the inner retina of bead injected eyes, relative to contralateral PBS-injected control eyes. Black bars represent PBS-injected and red bars represent Bead-injected $(n=5)$. C, COX histochemistry of retinal sections from PBS- and microbead-injected eyes $3 \mathrm{~d}$ after injection, showing that bead injection appears to decreases cytochrome Coxidase activity (DAB labeling) early in glaucoma $(n=5)$. $D$, Quantification of retinal DAB labeling from C, related to COX activity. E, Gene expression changes early in glaucoma show that (1) PBS injection does not appear to significantly alter gene expression relative to untreated retinas, and (2) bead injection increases the expression of several antioxidant and glaucoma-related genes, including $H$ mox 1, Nfe2l2, and $(10 a(n=3)$. IS, Inner segments; ONL, outer nuclear layer; $0 \mathrm{PL}$, outer plexiform layer; INL, inner nuclear layer; IPL, inner plexiform layer; $\mathrm{GCL}$, ganglion cell layer; $\mathrm{RNFL}$, retinal nerve fiber layer; Outer, outer retina; Inner, inner retina. ${ }^{*} p<0.05$, ${ }^{* *} p<0.01$.

transmembrane potential $\left(\Psi_{\mathrm{m}}\right)$, oxidative stress, and cell respiration using these astrocytes. We measured $\Psi_{\mathrm{m}}$ with the vital dye JC-1, which equilibrates in mitochondria as red fluorescent aggregates and outside as green fluorescent monomers. The ratio of aggregate/monomers is proportional to $\Psi_{\mathrm{m}}$, and we found that
Ucp 2 deletion $(n=7)$ increased $\Psi_{\mathrm{m}}$ to $120 \pm 7 \%$ of $U c p 2^{f l / f l}(n=$ $7)$ cells $(p=0.013, \mathrm{df}=15)$. As a control, we applied the membrane-permeant protonophore FCCP $(1 \mu \mathrm{M}, n=3)$, which reduced $\Psi_{\mathrm{m}}$ to $72 \pm 4 \%$ of controls $(p=0.013$, df $=15$; Fig. $3 C$ ). Oxidative stress was measured using $\mathrm{CM}-\mathrm{H}_{2}-\mathrm{DCFDA}$, a cell- 
A
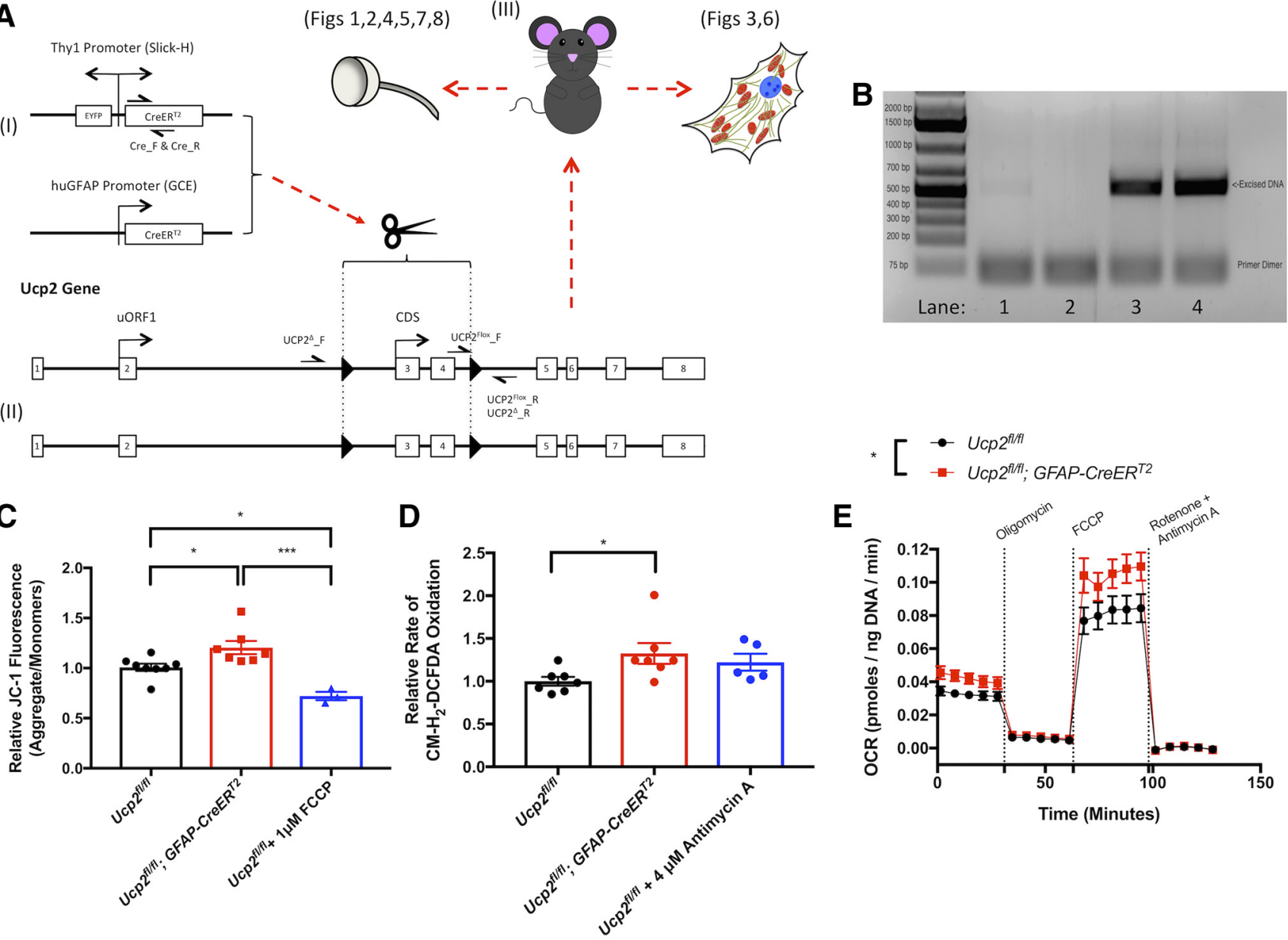

$\mathbf{E}$

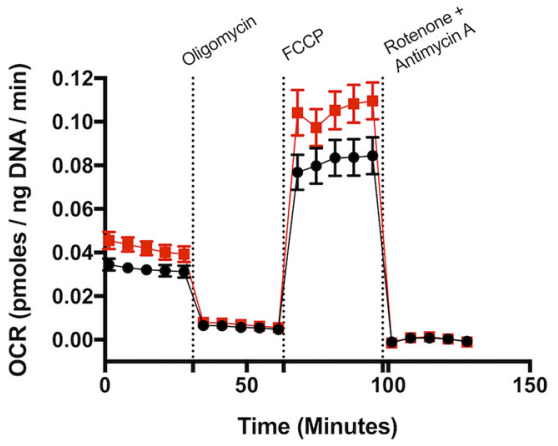

Figure 3. Cre-mediated $U c p 2$ excision increases $\psi_{\mathrm{m}}$, the rate of oxidant generation, and mitochondrial OCR in primary astrocytes. $A$, Schematic diagram of transgenic mouse genotypes for mice used in this study, the approximate primer locations for genotyping these animals, the region of DNA excised by CRE activity, tissues used from these mice, and the figures in which these tissues are used. $\boldsymbol{B}$, Example genotyping PCR of 4-hydroxytamoxifen-pretreated astrocytes from $U c p 2^{f / f f l}$ (lanes 1 and 2 ) and $U c p 2^{f / f f} ; G F A P$-creER ${ }^{T 2}$ (lanes 3 and 4 ) mice. The primers in this reaction only amplify when the $>1000 \mathrm{bp}$ LoxP-flanked region of the $U c p 2$ gene is removed. C, The JC-1 red/green fluorescence ratio in these primary astrocytes $(n=8)$ in increased by Ucp2 deletion $(n=7)$ and decreased by $1 \mu \mathrm{m} \mathrm{FCCP}(n=3)$, revealing that UCP2 normally functions to decrease $\psi_{\mathrm{m}}$ in these cells. $\boldsymbol{D}$, The rate of CM- $\mathrm{H}_{2}-\mathrm{DCFDA}$ oxidation is also increased with Ucp2 deletion $(n=7)$ or with $4 \mu \mathrm{m}$ antimycin $\mathrm{A}(n=5)$. E, Seahorse XF96 measurement of cellular OCR demonstrating that $U c p 2$ deletion increases the basal and maximal mitochondrial $0 C R$ of astrocytes, though not uncoupled respiration $(n=3) .{ }^{*} p<0.05,{ }^{* * *} p<0.005$.

permeant probe that becomes fluorescent upon oxidation, and we measured the rate $\left(\Delta \mathrm{F} / \mathrm{F}_{0}\right)$ of probe oxidation over $30 \mathrm{~min}$. Relative to $U c p 2^{f l / f l}$ controls, $U c p 2$ deletion increased oxidative stress to $133 \pm 12 \%(p=0.0452, \mathrm{df}=16, n=7)$. As a control to verify assay function, $U c p 2^{f l / f l}$ cells were treated with $4 \mu \mathrm{M}$ antimycin $A$, which nonsignificantly increased oxidative stress to $122 \pm 10 \%$ of controls $(p=0.13, \mathrm{df}=16, n=5$; Fig. $3 D)$. We measured OCR rate using a seahorse extracellular flux assay in $U c p 2^{f l / f l}$ and $U c p 2^{f l / f l} ; G F A P-c r e E R^{T 2}$ astrocytes. Following each assay, we normalized respiratory activity to DNA concentration. Basal respiration (untreated) over time was greater in $U c p 2^{f l / f l}$; GFAP-creER ${ }^{T 2}$ cells $(p<0.0001, \mathrm{df}=1, n=3)$, as was maximal respiration ( $p=0.0004, \mathrm{df}=1, n=3)$, suggesting unexpectedly greater mitochondrial function in cells lacking a functional copy of Ucp2 (Fig. 3E).

\section{Ucp2 deletion decreases RGC loss during glaucoma}

Cre-mediated $U c p 2$ deletion was confirmed by measuring retinal transcript levels, which decreased to $54 \pm 14 \%$ and $58 \pm 13 \%$ in $U c p 2^{f l / f l} ; G F A P-c r e E R^{T 2}$ and $U c p 2^{f l / f l} ;$ Thy1-creER $R^{T 2}$ mice, respectively, relative to $U c p 2^{f l / f l}$ controls (Fig. $4 A$ ). These extents of $U c p 2$ decrease were close to the expected value, as $U c p 2$ transcript ap- pears to be greatly expressed within cells of the inner retina (Fig. $1 A)$. Using reporter mice in which EGFP or YFP are coexpressed with $\mathrm{cre}$ recombinase, we confirmed the localization of these $\mathrm{cre}$ variants to retinal glia or ganglion cells (Fig. $4 B$ ). We injected beads in to mice with Ucp2 selectively deleted in Gfap- or Thy1expressing cells. On average, bead injection increased mean IOP by $9.5 \pm 1.5 \mathrm{mmHg}$ in $U c p 2^{f l / f l}$ mice, $3.1 \pm 0.7 \mathrm{mmHg}$ in $U_{c p} 2^{f l}$ fl:GFAP-creER ${ }^{T 2}$ mice, and $8.3 \pm 1.7 \mathrm{mmHg}$ in $U c p 2^{f l / f l}$;Thy1creER ${ }^{T 2}$ mice (Fig. $4 C$ ). In addition to our own data (Fig. $1 E$ ), others have demonstrated that the extent of IOP increase in the microbead model does not always correlate well with the extent of RGC loss (Cone et al., 2010), so differences in the extent of IOP increase between $U_{c p} 2^{f l / f l}, U_{c p} 2^{f l / f l} ;$ Thy1-creER $R^{T 2}$, and $U_{c p} 2^{f l / f l}$; $G F A P$-creER ${ }^{T 2}$ mice should not significantly alter the extent of RGC death. To determine the effect of Ucp2 deficiency on glaucomatous RGC death, we counted the density of RBPMS ${ }^{+}$RGCs on whole-mount retinas from $U c p 2^{f l / f l}, U c p 2^{f l / f l} ; G F A P-c r e E R^{T 2}$, and $U_{c p} 2^{f l / f l} ;$ Thy 1 -creER $R^{T 2}$ retinas (Fig. $4 D$ ). We determined the effect of glaucoma on RGC density using an ANOVA. A post hoc analysis revealed significant differences in bead-induced RGC loss between $U_{c p} 2^{\text {fllfl }}$ retinas $\left(607 \pm 148\right.$ cells $/ \mathrm{mm}^{2}$ in, $\mathrm{df}=50$, $n=29), U c p 2^{f l / f l} ; G F A P-c r e E R^{T 2}\left(79 \pm 195\right.$ cells $/ \mathrm{mm}^{2}, p=0.04$, 
A

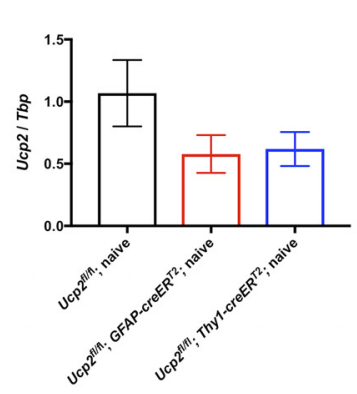

D
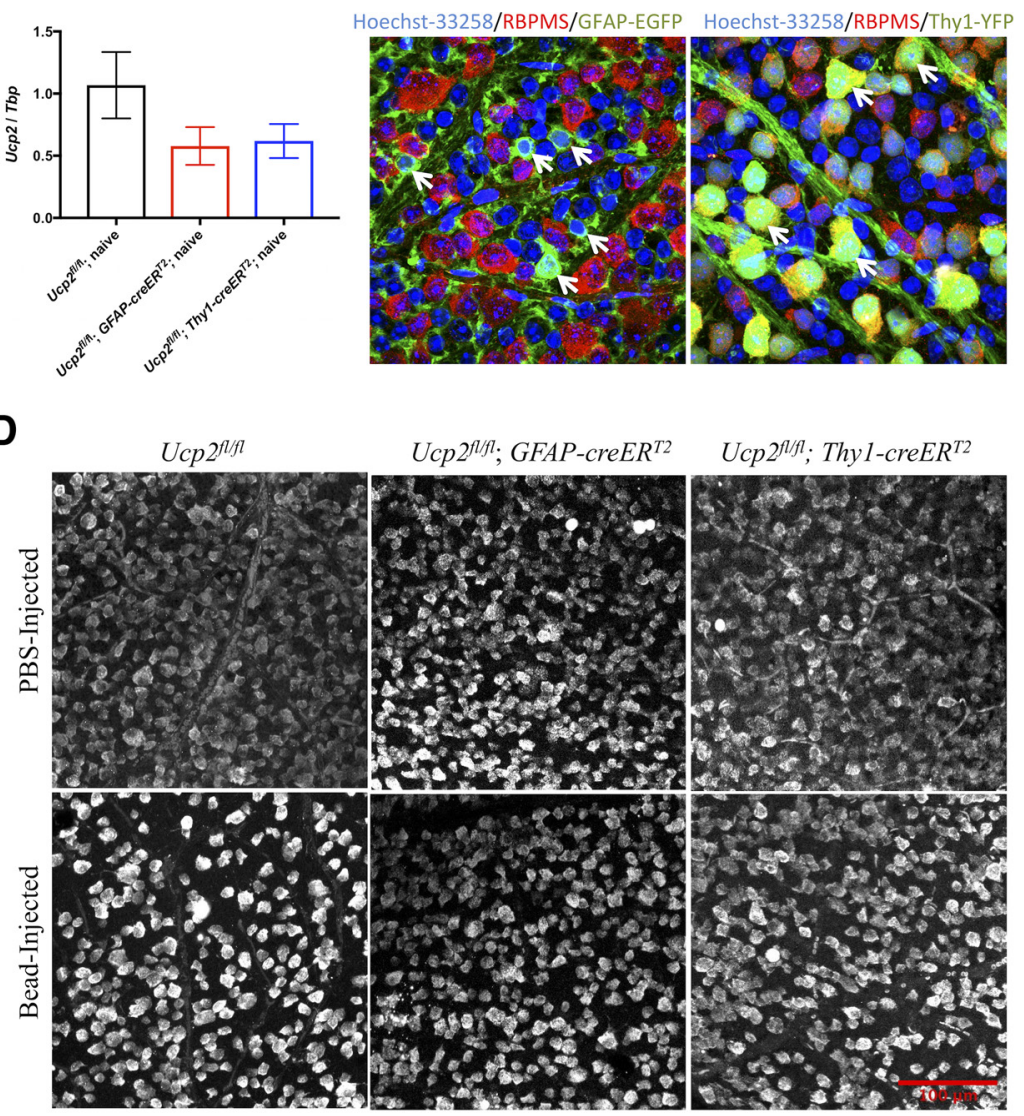

C

E

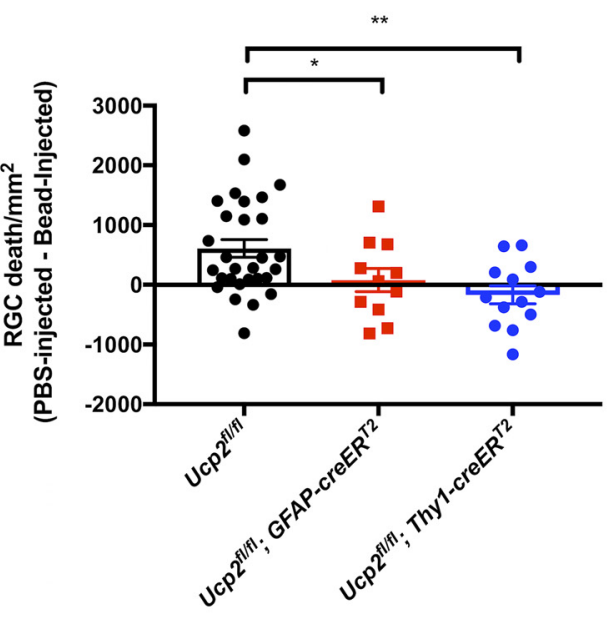

Figure 4. Ucp2 deletion in either glia or RGCs decreases RGC loss in glaucoma. $A, U c p 2$ expression in Ucp $2^{f / f f}, U c p 2^{f / f f} ; G F A P-c r e E R^{T 2}$, and $U c p 2^{f / f f l} ;$ Thy1-creER $R^{T 2}$ retinas, showing a decrease in $U c p 2$ expression in these transgenic mice. $\boldsymbol{B}$, Whole-mount retinas labeled with the nuclear label Hoechst-33258 (blue), the RGC marker RBPMS (red), and the endogenous fluorescence of EGFP in

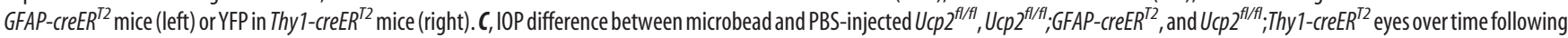
a single microbead injection. $D$, Example RBPMS-labeled RGCs in PBS- and bead-injected eyes from Ucp2 ${ }^{f / f f}(n=29), U c p 2^{f / f f} ; G F A P-c r e E R^{T 2}(n=10)$, and Ucp2 ${ }^{f / f f} ; T h y 1-c r e E R^{T 2}(n=13)$. Red scale bar, $100 \mu \mathrm{m}$. $E$, Differences in RGC density between PBS- and bead-injected eyes. A difference of 0 indicates no RGC death. ${ }^{*} p<0.05$, ${ }^{* *} p<0.01$.

$n=11)$, and $U c p 2^{f l f l} ; T h y 1-c r e E R^{T 2}$ retinas $(-169 \pm 151$ cells/ $\mathrm{mm}^{2}, p=0.0039, n=13$; Fig. $\left.4 D, E\right)$. These data suggest that, surprisingly, reduced retinal Ucp2 levels decreased RGC loss following IOP elevation.

To mitigate concerns that the lesser extent of IOP elevation in $U c p 2^{f l / f l}$;GFAP-creER $R^{T 2}$ mice is the reason that fewer RGCs are lost following bead injection, we analyzed RGC loss in a subset of bead-injected mice chosen such that mean IOP increases were close to those of $U c p 2^{f l / f l}$;GFAP-creER ${ }^{T 2}$ mice and $<0.1 \mathrm{mmHg}$ different between all groups. In this subset, $U c p 2$-dependent differences in RGC loss persisted, with a mean RGC loss of 695 cells $/ \mathrm{mm}^{2}$ in $\mathrm{Ucp}^{\mathrm{fl} / \mathrm{fl}}$ controls $(n=9),-79$ cells $/ \mathrm{mm}^{2}$ in $U c p 2^{f l / f l}$; GFAP-creER ${ }^{T 2}$ mice $(p=0.04, n=11)$, and -56 cells $/ \mathrm{mm}^{2}$ in $U c p 2^{f l f f l}$; Thy1-creER ${ }^{T 2}$ mice $(p=0.04, n=7)$. RGC loss in these subgroups was similar to the larger sample of mice, and these data suggest that the protective effect of Ucp2 governs RGC loss to a greater extent than does the degree of IOP elevation.

\section{The mechanism of Ucp 2 deletion-mediated neuroprotection}

To determine the effect of UCP2 on retinal oxidative stress, we measured HNE immunoreactivity in retinas of bead-injected eyes from $U_{c p} 2^{f l f l}, U_{c p} 2^{f l f f l} ; G F A P-c r e E R^{T 2}$, and $U_{c p} 2^{f l / f l} ; T h y 1-$ creER $R^{T 2}$ mice (Fig. 5A,B). Ucp $2^{f l f l} ;$ Thy1-creER $R^{T 2}(n=8)$ and $U c p 2^{f l f f} ; G F A P-c r e E R^{T 2}(n=7)$ accumulated significantly less $\operatorname{HNE}(p=0.02$ and $p=0.03$, respectively, $\mathrm{df}=20)$ than $U c p 2^{f l / f l}$ controls $(n=8)$, providing a quantitative proxy for the qualitative finding that the inner retina was less oxidatively damaged (Fig. 5B). Increases in retinal GFAP are a sign of Müller cell reactivity; and in $U c p 2^{f l / f l}$ mice, bead injection increased GFAP intensity to $239 \%$ of control $(p=0.0085, \mathrm{df}=61, n=13-23)$. In $U c p 2^{f l / f l} ; G F A P-c r e E R^{T 2}$ or $U c p 2^{f l f f l} ; T h y 1-c r e E R^{T 2}$, bead injection did not significantly increase our semiquantitative measure of GFAP labeling intensity, although there was a trend toward increase for each genotype (Fig. $5 C, D$ ). This is visualized in representative retinal sections of bead-injected transgenic mice, within which $\mathrm{GFAP}^{+}$Müller cell fibers are detectable but reduced in overall intensity relative to controls (Fig. $5 C$ ).

Neuroprotection of RGCs in transgenic mice was associated with a decrease in HNE labeling intensity, and we hypothesized that Ucp2 deletion altered mitochondrial dynamics or physiology in such a way as to reduce mitochondrial oxidant production. We labeled untreated $(n=5)$ and 4-hydroxytamoxifen $(1 \mu \mathrm{M})$ pretreated $(n=4)$ primary astrocytes from $U c p 2^{f l / f l}$;GFAP$c r e E R^{T 2}$ mice for the translocase of the outer mitochondrial membrane (TOMM20) to visualize mitochondrial dynamics (Fig. 6A). We quantified mean mitochondrial size, number, mass, and network size using the ImageJ plugin MiNA V1 (Valente et al., 2017). There was a nonsignificant trend toward decrease in overall mitochondrial mass per cell $(p=0.31$, $\mathrm{df}=7$; Fig. $6 B$ ), a significant decrease in the number of mitochondria/ 
A

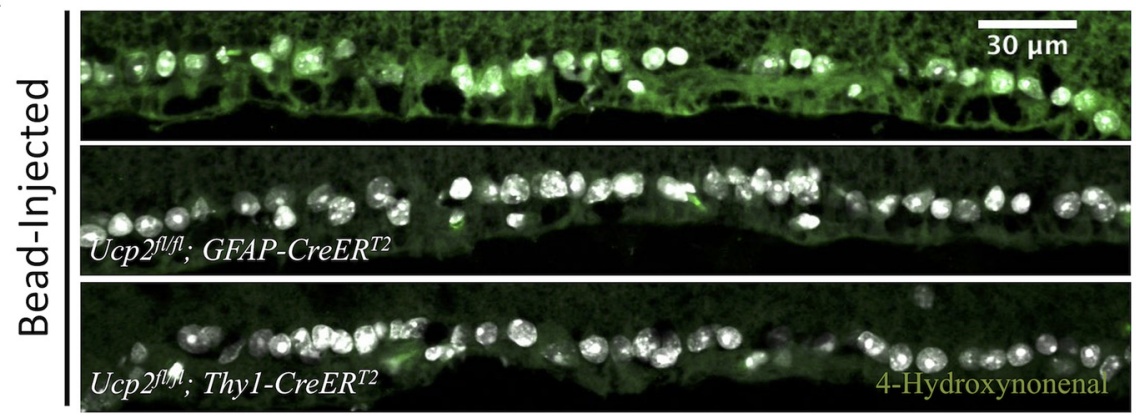

C

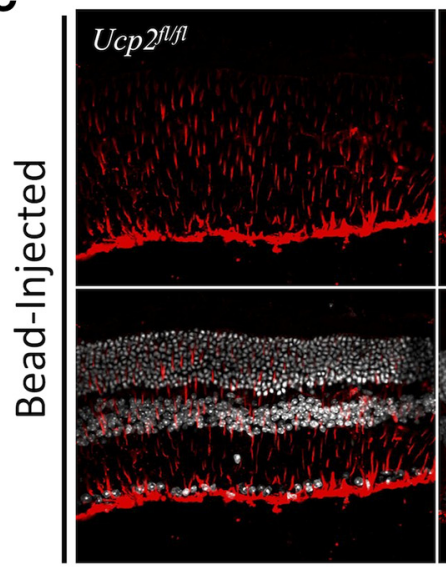

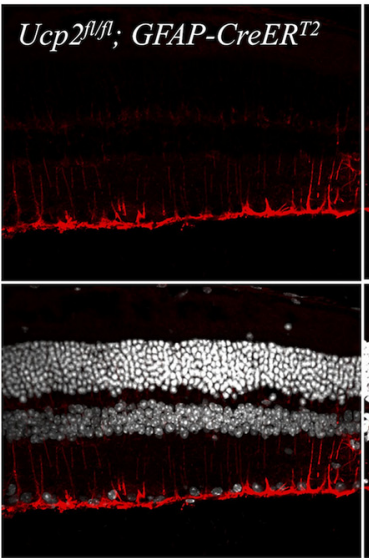

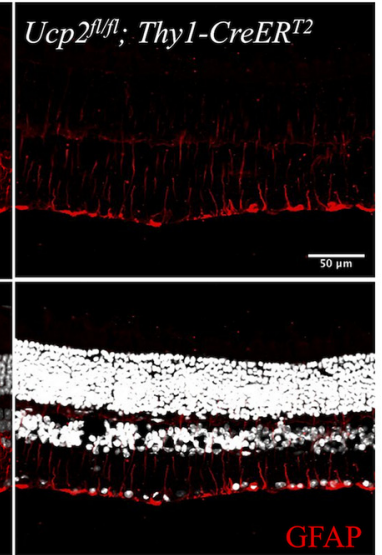

B
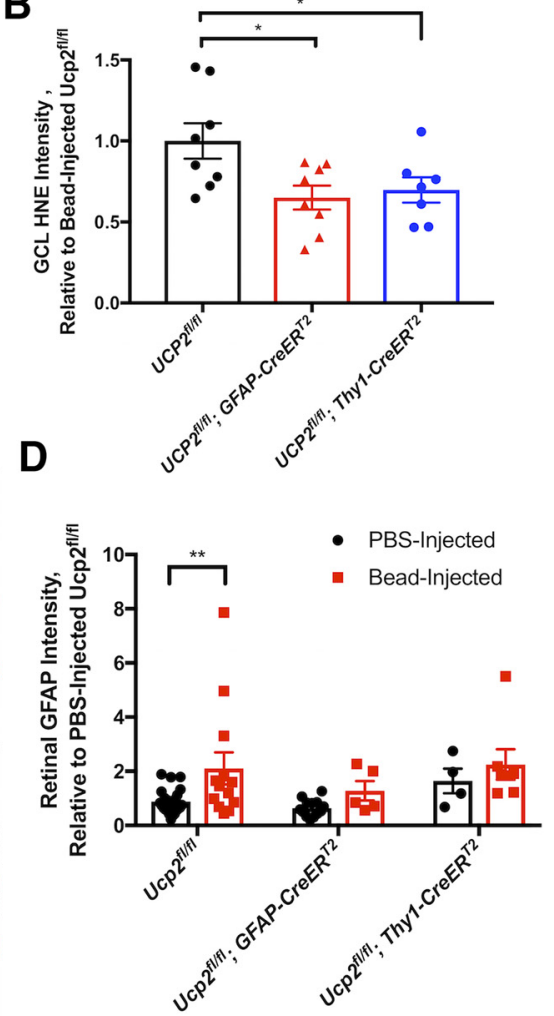

Figure 5. Ucp2 deletion in glia or RGCs decreases retinal oxidative stress and suppresses gliosis. Representative HNE (green) and Hoechst-33258 (blue)-labeled images ( $\boldsymbol{A}$ ) and quantification of HNE labeling in the inner retinas $(B)$ of bead-injected $U c p 2^{f / f f}(n=8), U c p 2^{f / f f} ; G F A P-c r e E R^{T 2}(n=7)$, and $U c p 2^{f / f f} ;$ Thy 1 -creER ${ }^{T 2}$ eyes $(n=8)$. These data show that the increase in HNE observed in glaucoma is decreased by Ucp2 deletion in either RGCs or GFAP-expressing astrocytes and Müller glia. Scale bar: A, $30 \mu \mathrm{m}$. C, Representative images of GFAP labeling of Müller glia and astrocytes of bead-injected $U c p 2^{f / f f l}(n=23), U c p 2^{f / f f l} ; G F A P-c r e E R^{T 2}(n=13)$, and $U c p 2^{f / f f} ;$ Thy 1-creER $R^{T 2}(n=7)$ retinas. D, Quantification of retinal GFAP labeling intensity corresponding to $C$. GFAP intensity

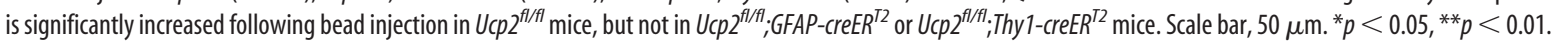

cell $(p=0.035$, df $=7$; Fig. $6 C)$, and an increase in mean area $(p=0.0061, \mathrm{df}=7$; Fig. $6 D)$. The overall number of mitochondrial networks/cell was unaltered. Together, the images of these mitochondria together with the quantified data suggest a slight increase the number of more fused mitochondria (Fig. 6A). A healthy pool of mitochondria is maintained through a balance of mitochondrial autophagy (mitophagy) and biogenesis (Piantadosi et al., 2008; Uittenbogaard and Chiaramello, 2014; Ito and Di Polo, 2017). The decrease in mitochondrial number could result from a decline in mitochondrial biogenesis, or an increase in the disposal of damaged mitochondria. We tested the first of these hypotheses by determining the expression of three genes involved in mitochondrial biogenesis, PolgA, Tfam, and PGC1- $\alpha$. These genes were not significantly altered by $U c p 2$ deletion in primary $U c p 2^{f l f l}$; GFAP-creER $R^{T 2}$ astrocytes, although the expression of nuclear and mitochondrial genes associated with mitochondrial function $(\mathrm{Cyt} B, \mathrm{Sod} 2)$ was significantly decreased $(p=$ 0.037 and $p=0.024$, respectively, $\mathrm{df}=27, n=3$ or 4 ; Fig. $6 E$ ).

We next tested whether the decrease in mitochondrial number and increase in size resulted from activation of mitophagy. We measured the subcellular distribution of the autophagosome adapter protein LC3B and the mitochondrial outer membrane marker Tomm20 in primary cultures of cortical astrocytes (Fig. $6 F, G)$. Using the Coloc2 plugin on ImageJ, we determined the Manders' overlap coefficient corresponding to the proportion of colocalized $\left(\mathrm{LC} 3 \mathrm{~B}+\mathrm{TOMM}_{20}{ }^{+}\right.$) pixels over TOMM $20^{+}$pixels (tM2). Ucp2 deletion significantly increased tM2 from $0.044 \pm$ 0.019 to $0.128 \pm 0.024$ ( $p=0.033, \mathrm{df}=6, n=3$ or 4 ; Fig. $6 G)$. $\mathrm{tM} 2$ also increased to a greater extent in $U c p 2^{f l / f l}$ astrocytes treated with $10 \mu \mathrm{M}$ FCCP for $3 \mathrm{~h}$, a treatment known to reproducibly induce mitochondrial fragmentation and mitophagy (0.246 \pm $0.074)$.

To recapitulate these findings in tissue, we reevaluated mitochondrial biogenesis in retinal tissue from $U c p 2^{f l / f l}, U c p 2^{f l / f}$; GFAP-creER $R^{T 2}$, and $U c p 2^{f l / f l}$; Thy 1 -creER $R^{T 2}$ mice, by measuring the expression of PolgA, Tfam, and PGC1- $\alpha$. Similar to our findings in primary cortical astrocytes, we found no differences in the expression of these factors (Fig. 7A). We also measured the expression of several factors related to mitophagy in the retinas of bead- and PBS-injected transgenic mice (Fig. $7 B ; n=3$ /group). We observed genotype- and condition-specific increases in the expression of Pink1, Park2, Bnip3L, and Lc3b. Specifically, there was an overall significant increase in Pinkl expression in $U c 2^{f / f / f}$; Thy1-creER $R^{T 2}$ mice regardless of bead injection $(p=0.038)$, a general increase in Park2 expression in Ucp $2^{f l / f l}$; GFAP-creER ${ }^{T 2}$ mice, which was only significant following bead injection $(p=$ $0.016)$. Bnip $3 l$ was nonsignificantly elevated in $U c p 2^{f l / f l} ; G F A P$ $c r e E R^{T 2}$ retinas, but only with PBS injection $(p=0.087)$. Conversely, Bnip3l expression was significantly elevated in the retinas from bead-injected $U c p 2^{f l f l f}$; Thy1-creER $R^{T 2}$ mice but not in PBSinjected controls $(p=0.039)$. Lc3b expression significantly increased in bead-injected $U c p 2^{f l / f l} ; G F A P-c r e E R^{T 2}$ retinas $(p=$ $0.02)$ and reached a near significant increase in $U c p 2^{f l f f l} ;$ Thy1creER ${ }^{T 2}$ retinas $(p=0.058)$. The expression results suggest that there is an increase in retinal mitophagy following $U c p 2$ deletion, but the specific cell type and environment from which Ucp2 is deleted will dictate which components of mitophagy machinery are altered. 

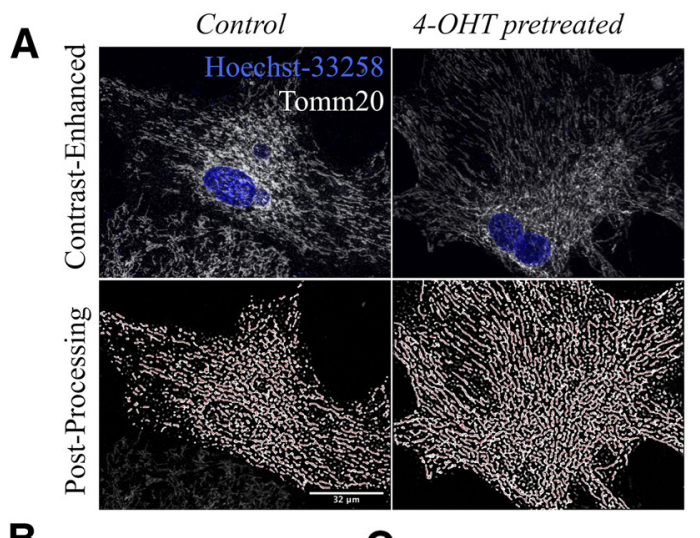

B

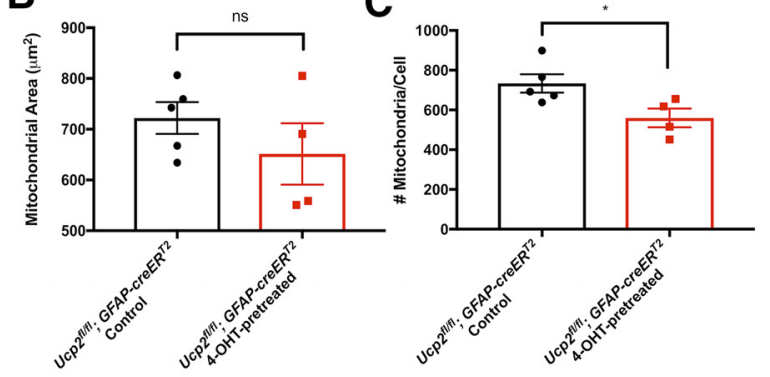

D

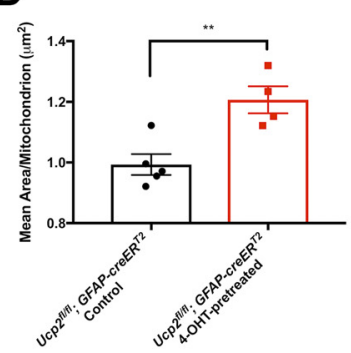

$\mathbf{F}$
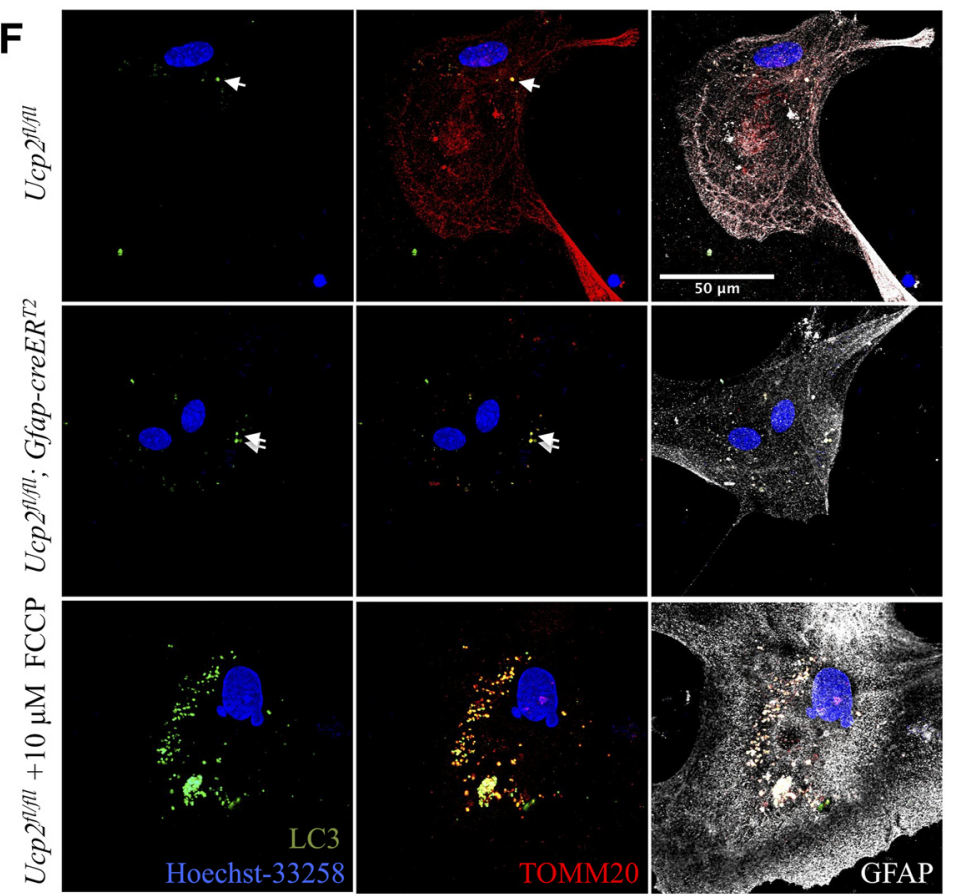

G

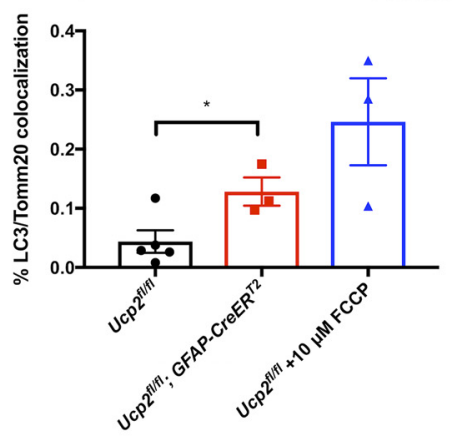

Figure 6. Ucp2 deletion does not alter mitochondrial biogenesis and increases mitophagy. $\boldsymbol{A}$, Contrast-enhanced and auto-segmented images of Hoechst-33258 (blue)- and T0MM20 (white)labeled mitochondria in control and 4-hydroxytamoxifen-pretreated $U c p 2^{f / / f l} ; G F A P-c r e E R^{T 2}$ primary cortical astrocytes. $\boldsymbol{B}-\boldsymbol{E}$, Quantification of morphology through measurement of $(\boldsymbol{B})$ mean mitochondrial area per cell $\left(\mu \mathrm{m}^{2}\right),(\boldsymbol{C})$ the number of mitochondria per cell, and $(\boldsymbol{D})$ mean area per mitochondrion $\left(\mu \mathrm{m}^{2}\right)(n=5$ biological replicates, derived from different mice with $\geq 6$ cells per biological replicate). Scale bar, $32 \mu \mathrm{m}$. E, Expression of genes associated with mitochondrial biogenesis and function in cultured astrocytes, showing that $U(p 2$ deletion does not increase biogenesis but does decrease the expression Sod2 and cytochrome B $(n=4)$. Representative images $(\boldsymbol{F})$ and quantification of colocalization $(\boldsymbol{G})$ between LC3B (green) and TOMM20 (red) in Ucp2 ${ }^{f / f f l}(n=5)$ and $U c p 2^{f / f f}$; Gfap-creER ${ }^{T 2}$ astrocytes $(n=3)$, showing a significant increase in colocalization with $U c p 2$ deletion. Cell identity was confirmed using the astrocyte marker GFAP (white) and the DNA label Hoechst-3328 (blue). Image scale is the same as in $A .{ }^{*} p<0.05,{ }^{* *} p<0.01$.

We measured protein levels of both nonlipidated (LC3B-I) and lipidated (LC3B-II) forms of LC3B (Fig. 8A), and found a significant increase in LC3B-II within both PBS- and beadinjected retinas $U c p 2^{f l f f} ;$ Thy $1-c r e E R^{T 2}$ retinas $(p=0.029$ and $p=$ 0.0015 , respectively, $\mathrm{df}=15, n=3$ or 4/group; Fig. $8 B$ ). We also noticed an increase in total LC3B levels in the PBS- and beadinjected retinas of both $U c p 2^{f l / f l} ; G F A P-c r e E R^{T 2}(p=0.0002$ and $p=0.014$, respectively, $\mathrm{df}=15, n=3$ or 4$)$ and $U_{c p} 2^{\text {flffl }}$; Thy1$\operatorname{creER}^{T 2}$ ( $p=0.021$ and $p=0.005$, respectively, $\mathrm{df}=15, n=3$ or 4) mice (Fig. 8C). The ratio of LC3B-II/LC3B-I was not significantly altered by $U c p 2$ deletion in either PBS- or bead-injected retinas, suggesting no change in the flux of autophagic cargo (Fig. $8 D)(n=3$ or 4$)$. When we studied the effect of $U c p 2$ deletion on BNIP3L (Fig. 8E), we found a significant increase in BNIP3L within both transgenic strains ( $p=0.033, \mathrm{df}=14, n=3$ or 4 for $U c p 2^{f l / f l} ; G F A P-c r e E R^{T 2}$ and $p=0.033$, df $=14, n=3$ or 4 for $U c p 2^{\text {flffl }} ;$ Thy1-creER $R^{T 2}$ ), but this increase was exclusive to PBSinjected control eyes (Fig. $8 F$ ). Notably, the most clearly defined bands in BNIP3L blots migrated at 76 and $100 \mathrm{kDa}$, respectively, corresponding to the BNIP3L dimer (Chen et al., 2010) and a nonspecific band. Analysis of protein levels was performed exclusively on the $76 \mathrm{kDa}$ band, although analysis of the whole lane $<100 \mathrm{kDa}$ yielded almost identical relative protein density values.

The RNA and protein expression data yield differing accounts of the molecular events that occur following neural or glial Ucp2 deletion, and we wanted to determine whether these expression changes led to an increase in autophagosomes in retinal tissue. Within this tissue, mitochondria are too dense for an accurate colocalization analysis of a mitochondrial marker with LC3B, so we determined the density of autophagosomes in retinas from bead-injected $U c p 2^{f l / f l}, U c p 2^{f l / f l} ; G F A P-c r e E R^{T 2}$, and $U c p 2^{f l / f l}$; Thy1-creER ${ }^{T 2}$ mice. Retinal tissue from $U c p 2$-deleted mice generally labeled more strongly than $U_{c p} 2^{\text {flffl }}$ tissue, which is consistent with an increase in total LC3B protein. In addition to the increase in background LC3B levels, bead-injected transgenic retinal tissue had significantly more LC3B puncta relative to beadinjected $U_{c p} 2^{\text {fllfl }}$ controls. The regional distribution of the increase in these puncta was unique for each cre variant. The 

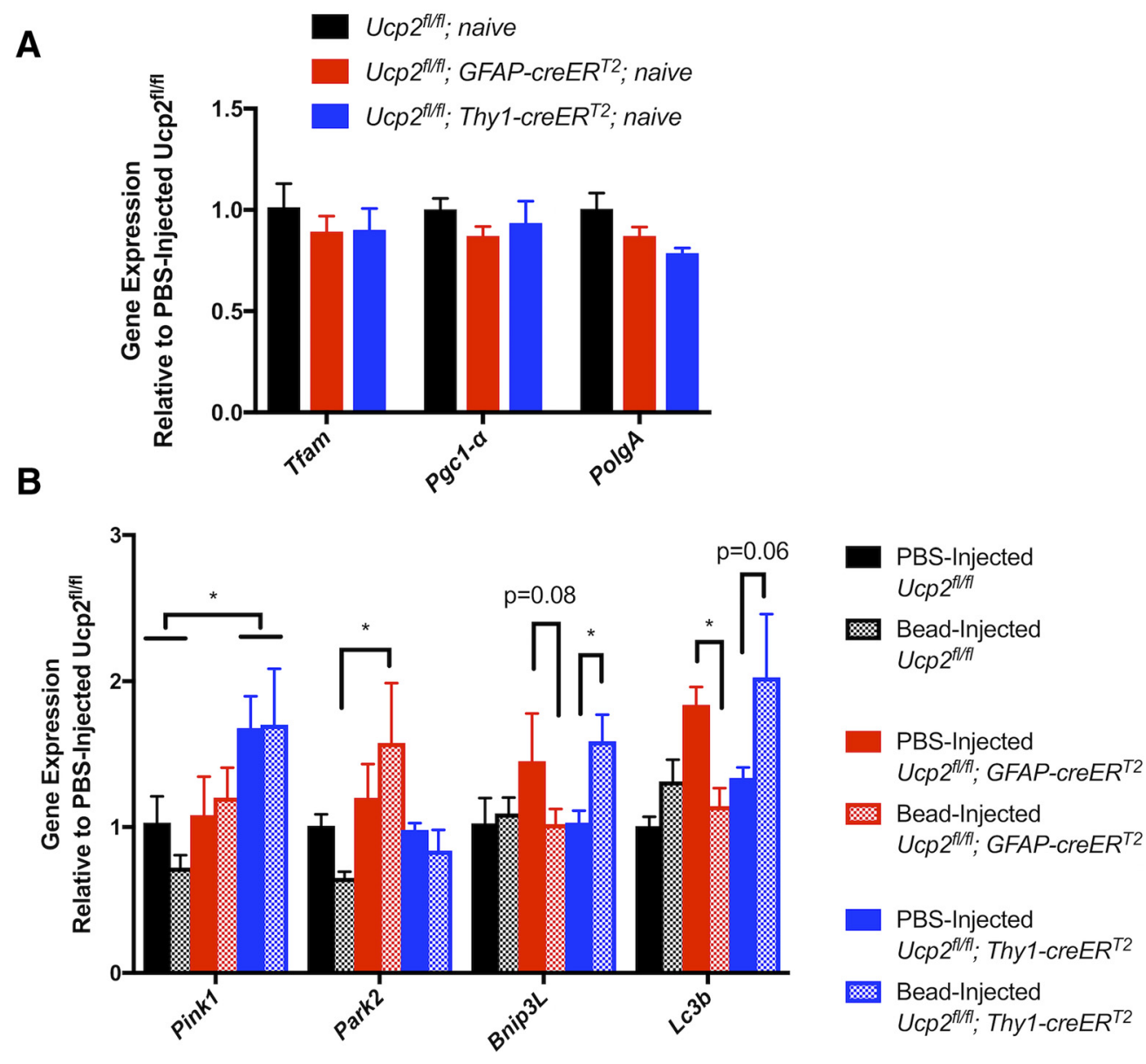

Figure 7. Ucp2 deletion increases the expression of mitophagy-related genes without altering mitochondrial biogenesis. $A$, Expression of the mitochondrial biogenesis-related genes in retinas from $U c p 2^{f / / f l}, U c p 2^{f / / f} ; G F A P-c r e E R^{T 2}$, and $U c p 2^{f / / f l} ; T h y 1-c r e E R^{T 2}$ mice. There was no significant change in expression of these genes between mouse lines, although there appears to be a trend toward a decrease in the expression of these factors in the retinas of $U c p 2^{f / f l} ; G F A P$-creER $R^{T 2}$ and $U c p 2^{f / f f}$;Thy1-creER $R^{T 2}$ mice $(n=3)$. B. Expression of the mitophagy-related genes Pink1, Park2, Bnip3l, and $L c 3 b$ in $U c p 2^{f / f t} ; G F A P$-creER ${ }^{T 2}$ and $U c p 2^{f / f f}$; Thy1-creER ${ }^{T 2}$ retinas from PBS-injected (black) and bead-injected (red) eyes, relative to Ucp2 ${ }^{f / f l}$ control retinas $(n=3)$. Two-way ANOVAs were performed for each gene, accounting for transgene and type of injection (PBS or bead) as independent variables. Bead injection alone did not have a significant effect on any of these genes, genetic background significant impacted Pink 1 expression, and the interaction between bead injection and genetic background for $L C 3 b$ and Bnip3/ expression. A posthoc analysis of each gene revealed other differences in expression, labeled in the figure. ${ }^{*} p<0.05$.

density of $\mathrm{LC} \mathrm{B}^{+}$autophagosomes increased to a greater extent within the outer retina in $U c p 2^{f l f l} ; G F A P-c r e E R^{T 2}$ mice $(p=$ $0.044, \mathrm{df}=5, n=3$ or 4 ; Fig. $8 G$ ), although there were nonsignificant increases in the inner retinas of these mice, which may be more clearly resolved with a larger number of replicates. Conversely, in bead-injected $U c p 2^{\text {fllfl }}$; Thy $1-c r e E R^{T 2}$ retinas, the increase in LC3B puncta density was restricted to the inner retina, which contains RGC soma, dendrite, and axon mitochondria $(p=0.01, \mathrm{df}=4, n=3$; Fig. $8 H)$. Together, the data suggest that Ucp2 deletion increases mitochondrial autophagy in the retina.

\section{Discussion}

Mitochondrial dysfunction and oxidative stress are central to the pathophysiology of glaucoma and have been observed in both animal models and human tissue (Moreno et al., 2004; Malone and Hernandez, 2007; Lee et al., 2011; Mousa et al., 2015; Khawaja et al., 2016). Following a microbead injection, we confirmed the role of elevated IOP in RGC death (Fig. 1), mitochondrial dysfunction, and oxidative stress (Fig. 2).

Previous studies have shown that greater levels of Ucp2 expression are protective against various conditions that increase oxidative stress, including excitotoxicity and MPTP-induced parkinsonism (Diano et al., 2003; Andrews et al., 2005; Barn- stable et al., 2016). We have found that UCP2 is expressed in the inner retina (Fig. 1A), an area greatly affected by oxidative stress in glaucoma (Izzotti et al., 2003; Moreno et al., 2004), and have verified the role of UCP2 in regulating cellular $\Psi_{\mathrm{m}}$ and oxidative stress (Fig. 3C,D). Müller glia, astrocytes, and RGCs all exist within the inner retina, and each regulates the bioenergetic and oxidative status of ganglion cells (Kawasaki et al., 2000), which is why we modeled glaucoma in mice where Ucp2 was selectively depleted in Gfap-expressing (astrocytes and Müller glia) or in Thy1-expressing cells (RGCs; Fig. 4A,B).

We increased the IOP of these mice by injecting microbeads and found that, while an elevated IOP may increase RGC loss, reactive gliosis, and oxidative retinal damage in $U c p 2^{f l f l}$ control mice, $U c p 2^{f l / f l} ; G F A P-c r e E R^{T 2}$ and $U c p 2^{f l / f l} ; T h y 1-c r e E R^{T 2}$ were protected from these phenotypes (Figs. 4, 5). This finding, while not unprecedented (de Bilbao et al., 2004), was surprising, as Ucp2 overexpression is neuroprotective in retinas exposed to excitotoxic factors (Barnstable et al., 2016), and the reverse genetic manipulation was expected to have the opposite effect. To determine the source of the observed neuroprotective phenotype, we monitored the mitochondrial morphology of Ucp2-deficient cells. The mitochondria of these cells appeared to be in a more 


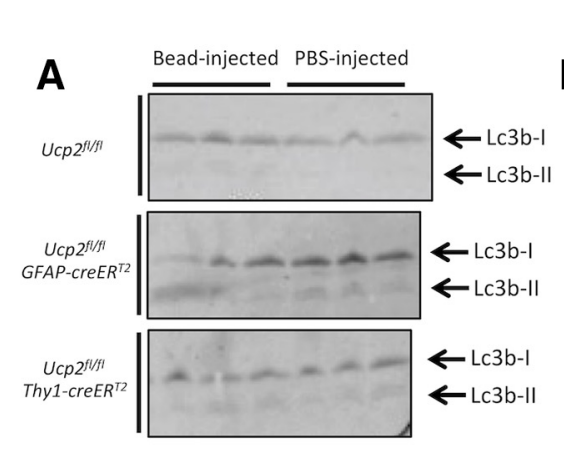

$\square U_{c p 2^{\text {I/R }}}$
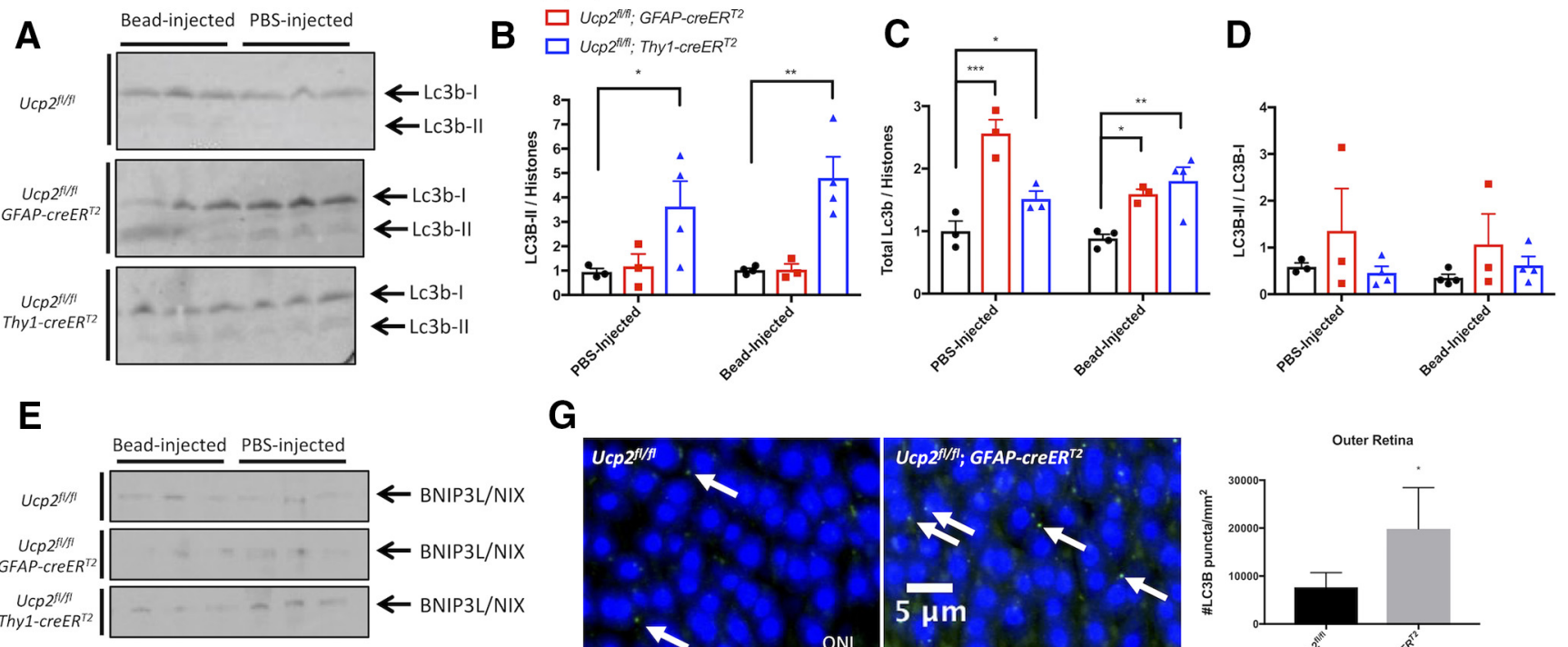

\section{G}
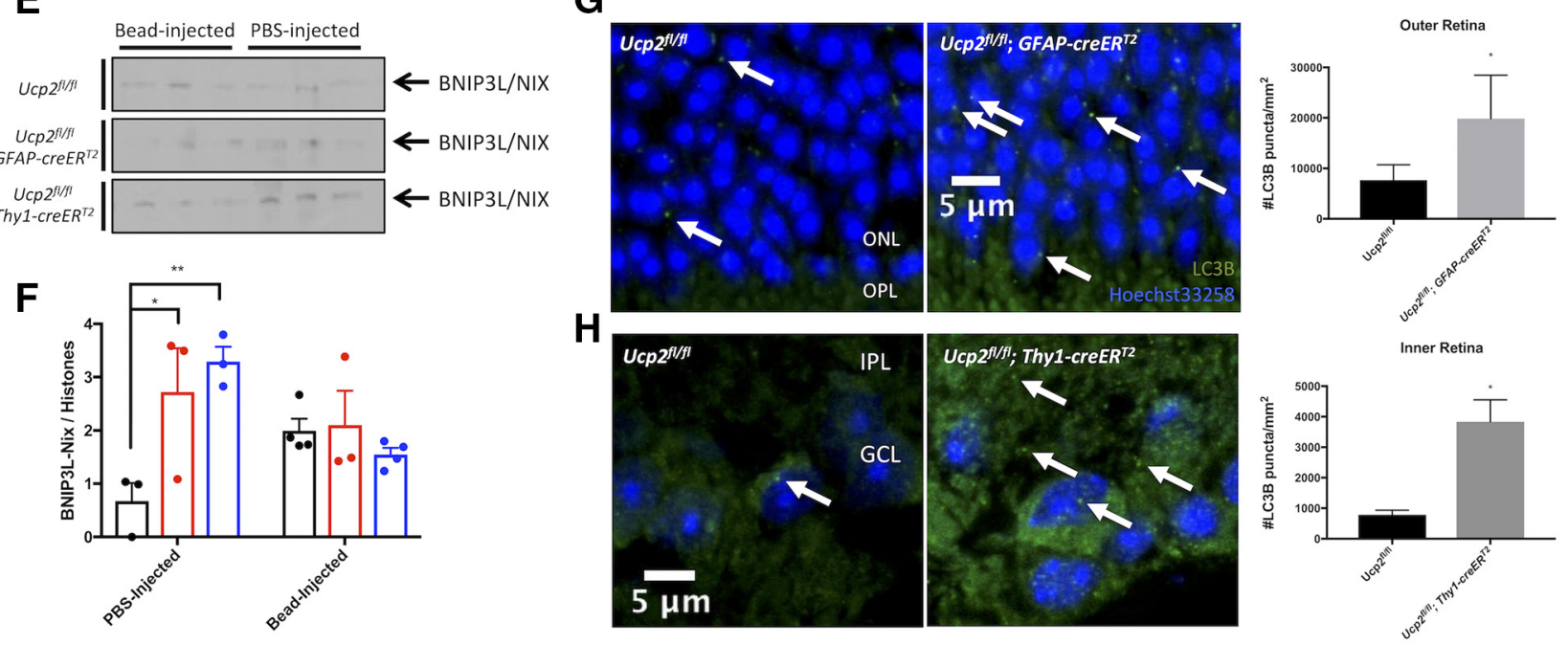

Figure 8. Ucp2 deletion increases $L\left(C B\right.$ protein and retinal mitophagy. $A, D$, Western blot of protein extracts from bead- and PBS-injected Ucp $2^{f / f f}$ (black bars, $n=3$ or $4 / g$ group), Ucp $2^{A / f f f} ; G F A P$ creER $^{T 2}$ (red bars, $n=3 /$ group), and Ucp2 ${ }^{f / f} ;$; Thy 1 -creER ${ }^{T 2}$ (blue bars, $n=3$ or 4/group) retinas, labeled for LC3B-I and LC3B-II (A) as well as BNIP3L/NIX (E). B-D, $\boldsymbol{F}$, Corresponding quantification of protein levels for both PBS- and bead-injected retinas. $B$, LC3B-II was significantly elevated in both PBS- and bead-injected UCP2 ${ }^{f / f l} ;$;hy $1-$ creER $^{T 2}$ retinas. C, Total LC3B levels were significantly elevated in PBS- and bead-injected retinas from both Ucp2 $2^{f / f} ;$; Thy 1-creER ${ }^{T 2}$ and $U c p 2^{f / f / f} ; G F A P-c r e E R^{T 2}$ mice. D, LC3B-II/LC3B-I were unchanged with Ucp2 deletion. F, BNIP3L/NIX was significantly elevated in PBS-injected retinas of both cre-expressing transgenic mice, but not with bead injection. $\mathbf{G}, \boldsymbol{H}$, We also labeled LC3B (green) and DNA (Hoechst-33258, blue) in retinal tissue from Ucp $2^{f / f l}$ $(n=4), U c p 2^{f / f / f} ; G F A P-c r e E R^{T 2}(n=3)$, and $U c p 2^{f / f / f} ; T h y 1-c r e E R^{T 2}(n=3)$ mice. Right, Example images. Left, Quantifications of LC3B puncta density. Compared with the same regions of $U c p 2^{f / f f l}$ retinas, LC3B puncta significantly increase in the outer retinas of $U C p 2^{f / / f l} ; G F A P-c r e E R^{T 2}$, and in the inner retinas of $U c p 2^{f / f f l} ;$ Thy1-creER $R^{T 2}$ mice. ${ }^{*} p<0.05$, ${ }^{* *} p<0.01$, ${ }^{* * *} p<0.005$.

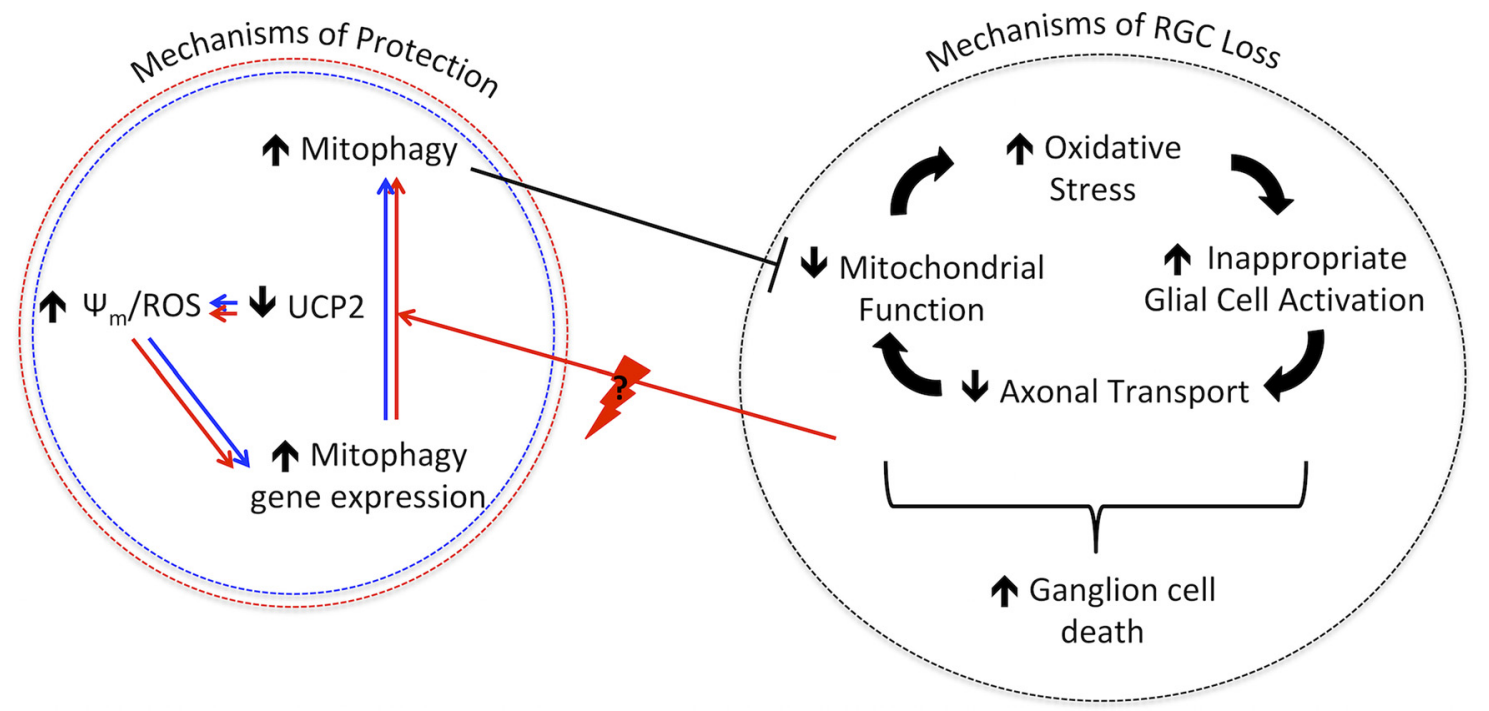

Figure 9. The proposed model for Ucp2 deletion-mediated neuroprotection. Schematic diagram showing the interplay of oxidative stress, decreased mitochondrial function, decreased axonal transport, and altered glial cell activation, all of which are known to play pathophysiological roles in glaucoma and several other neurodegenerative conditions. These factors all contribute to each other and to RGC death. Our proposed mechanism to explain the protective effects of Ucp2 deletion is by this alteration leading to a $\Psi_{\mathrm{m}}$-and ROS-dependent increase in mitophagy, occurring both through increases in mitophagy gene expression and changes in protein levels, which provide a pool of mitophagy components and increase the disposal of damaged mitochondria either at baseline when Ucp 2 is deleted in RGCs (blue) or in inducibly in Gfap-expressing glia (red). Thunderbolt enclosing a "?" indicates the stimulus that causes the more dynamic changes in glial mitophagy. In this model, the increase in mitophagy cuts short degenerative phenomena that result from dysfunctional mitochondria, and decreases cellular damage. 
fused state (Fig. $6 A, D$ ) and exhibited an elevated respiratory capacity (Fig. $3 E$ ), suggesting that mitochondrial function was bolstered by Ucp2 deletion. This led us to investigate the role that Ucp2 plays in regulating cellular and retinal mitochondrial dynamics.

Health of the mitochondrial population is maintained in part by mitochondrial biogenesis, which can generate new and undamaged mitochondria, and also by mitochondrial autophagy (also known as mitophagy) (Lemasters, 2005), which selectively disposes of damaged or dysfunctional mitochondria, which are smaller and have generally undergone fission (Kim et al., 2007; Frank et al., 2012). Our data did not suggest that Ucp2 altered the transcription of factors associated with mitochondrial biogenesis, either in cells (Fig. 6E) or in retinal tissue (Fig. 7A). We then measured mitophagy in astrocytes, through the association of mitochondrial and autophagosomal proteins TOMM20 and LC3B. We found a positive indication that mitochondrial components were being degraded more in Ucp2-deficient cells $(6 \mathrm{~F}$ $\mathrm{G})$, which was well supported by a previous study of Ucp2 deletion in pulmonary endothelial cells (Haslip et al., 2015). Our cellular data were generally supported by increases in the expression of several mitophagy-related genes in vivo (Fig. 7B), although notably these expression profiles did not always correspond with increases in mitophagy or autophagy protein markers. Transcriptional profiling is infrequently used to monitor mitophagy, but the discrepancy between gene expression and gene product levels is still important for studies aiming to translate their findings to the clinic by altering the regulation of mitophagy. In that regard, we do show that Ucp2 levels may regulate expression of mitophagy genes.

We supported the gene expression data by measuring protein levels of LC3B-II, a lipidated form of the protein that is anchored in autophagosome membranes (Tanida et al., 2004), as well as the mitochondrial membrane-integral LC3B adaptor BNIP3L (also known as NIX), a more selective mark of mitophagy rather than generalized autophagy (Sandoval et al., 2008; Chen et al., 2010; Novak et al., 2010; Johansen and Lamark, 2011). Ucp2 deletion in Thy1-expressing neurons had a particularly large impact on protein levels of LC3B-II, and it is unclear why the same effect was undetectable in $U c p 2^{f l / f l}$;GFAP-creER $R^{T 2}$ retinal tissue, particularly given that levels of BNIP3L do increase in this tissue (Fig. $8 D, E$ ), and the density of $\mathrm{LC}_{3} \mathrm{~B}^{+}$autophagosomes also increases in immunolabeled retinal sections (Fig. $8 F, G$ ). These data, however, are based on tissue exposed to elevated IOPs for different periods of time. Protein expression data are based on tissue isolated $3 \mathrm{~d}$ after bead injection, and LC3B puncta counts were from tissue isolated $30 \mathrm{~d}$ after bead injection; and together, the data suggest that, while their autophagic and mitophagic markers are always elevated in $U c p 2^{f l f l}$;Thy1-creER $R^{T 2}$ retinas, their expression is likely much more dynamic in $U c p 2^{f l / f l}$;GFAP-creER $R^{T 2}$ retinal tissue. Of note is the finding that, while total LC3B levels appear to always be elevated, Ucp2 deletion had no effect on mitophagic flux, measured by retinal LC3B-II/LC3B-I. Together, these data suggest that, while there is a larger pool of available LC3B protein that leads to an increase in autophagosome number, the rate at which individual autophagosomes degrade mitochondria or other molecules is probably unaltered by Ucp2 deletion.

The observed increase in mitophagy stimulated by Ucp2 deletion is likely a source of neuroprotection. Mitophagy is already decreased in the glaucomatous mouse optic nerve (Coughlin et al., 2015), and Ucp2 deletion may be protective by rebalancing baseline levels of mitophagy. Similarly, overexpression of the E3 ubiquitin ligase Parkin in the rat retina stimulates retinal mi- tophagy and is also protective against glaucomatous RGC death (Dai et al., 2018). Therefore, the RGC-intrinsic increases in mitophagy following $U c p 2$ deletion are probably directly protective, although our investigations in $U c p 2^{f l l f l} ; G F A P-c r e E R^{T 2}$ mice led us to the critical question of how glial mitophagy can protect RGCs from oxidative stress and cell death.

Retinal glia are phagocytic (Bejarano-Escobar et al., 2017), and astrocytes of the optic nerve head are able to dispose of damaged RGC mitochondria under physiological conditions (Davis et al., 2014), which leads us to the hypothesis that a Ucp2 deletion-dependent increase in glial mitophagy increases the transcellular disposal of RGC mitochondria. To determine whether this is the case in future studies, we will need a sophisticated methodology that combines transgenic Ucp2 deletion in glia with a molecular probe targeted to RGC mitochondria. With this setup, we could determine whether modulation of glial $U c p 2$ expression increases the density of RGC mitochondria engulfed by glia.

Our data point to a noncanonical function for $U c p 2$, and perhaps for uncoupling proteins in general. While they decrease oxidative damage when active, uncoupling protein inactivity may promote a sublethal form of oxidative damage that triggers mitophagy (Frank et al., 2012), specifically selecting dysfunctional mitochondria for degradation (Lemasters, 2005; Kim and Lemasters, 2011). This activity could result in cells enriched for undamaged mitochondria, which we see when imaging mitochondria. This model is represented in Figure 9. Overall, we suggest that, as a consequence of regulating mitochondrial ROS homeostasis, $U c p 2$ is also a regulator of mitochondrial dynamics.

\section{References}

Adachi H, Tominaga H, Maruyama Y, Yoneda K, Maruyama K, Yoshii K, Kinoshita S, Nakano M, Tashiro K (2015) Stage-specific reference genes significant for quantitative PCR during mouse retinal development. Genes Cells 20:625-635.

Andrews ZB, Horvath B, Barnstable CJ, Elsworth J, Yang L, Beal MF, Roth RH, Matthews RT, Horvath TL (2005) Uncoupling protein-2 is critical for nigral dopamine cell survival in a mouse model of Parkinson's disease. J Neurosci 25:184-191.

Arsenijevic D, Onuma H, Pecqueur C, Raimbault S, Manning BS, Miroux B, Couplan E, Alves-Guerra MC, Goubern M, Surwit R, Bouillaud F, Richard D, Collins S, Ricquier D (2000) Disruption of the uncoupling protein-2 gene in mice reveals a role in immunity and reactive oxygen species production. Nat Genet 26:435-439.

Barnstable CJ, Reddy R, Li H, Horvath TL (2016) Mitochondrial uncoupling protein 2 (UCP2) regulates retinal ganglion cell number and survival. J Mol Neurosci 58:461-469.

Bejarano-Escobar R, Sánchez-Calderón H, Otero-Arenas J, Martín-Partido G, Francisco-Morcillo J (2017) Müller glia and phagocytosis of cell debris in retinal tissue. J Anat 231:471-483.

Boland MV, Quigley HA (2007) Risk factors and open-angle glaucoma: classification and application. J Glaucoma 16:406-418.

Bouillaud F, Couplan E, Pecqueur C, Ricquier D (2001) Homologues of the uncoupling protein from brown adipose tissue (UCP1): UCP2, UCP3, BMCP1 and UCP4. Biochim Biophys Acta 1504:107-119.

Carter-Dawson L, Shen F, Harwerth RS, Smith EL 3rd, Crawford ML, Chuang A (1998) Glutamine immunoreactivity in Müller cells of monkey eyes with experimental glaucoma. Exp Eye Res 66:537-545.

Chen Y, Lewis W, Diwan A, Cheng EH, Matkovich SJ, Dorn GW 2nd (2010) Dual autonomous mitochondrial cell death pathways are activated by Nix/BNip3L and induce cardiomyopathy. Proc Natl Acad Sci U S A 107: 9035-9042.

Cone FE, Gelman SE, Son JL, Pease ME, Quigley HA (2010) Differential susceptibility to experimental glaucoma among 3 mouse strains using bead and viscoelastic injection. Exp Eye Res 91:415-424.

Cone FE, Steinhart MR, Oglesby EN, Kalesnykas G, Pease ME, Quigley HA (2012) The effects of anesthesia, mouse strain and age on intraocular 
pressure and an improved murine model of experimental glaucoma. Exp Eye Res 99:27-35.

Coughlin L, Morrison RS, Horner PJ, Inman DM (2015) Mitochondrial morphology differences and mitophagy deficit in murine glaucomatous optic nerve. Invest Ophthalmol Vis Sci 56:1437-1446.

Dai Y, Hu X, Sun X (2018) Overexpression of parkin protects retinal ganglion cells in experimental glaucoma. Cell Death Dis 9:88.

Davis CH, Kim KY, Bushong EA, Mills EA, Boassa D, Shih T, Kinebuchi M, Phan S, Zhou Y, Bihlmeyer NA, Nguyen JV, Jin Y, Ellisman MH, MarshArmstrong N (2014) Transcellular degradation of axonal mitochondria. Proc Natl Acad Sci U S A 111:9633-9638.

de Bilbao F, Arsenijevic D, Vallet P, Hjelle OP, Ottersen OP, Bouras C, Raffin Y, Abou K, Langhans W, Collins S, Plamondon J, Alves-Guerra MC, Haguenauer A, Garcia I, Richard D, Ricquier D, Giannakopoulos P (2004) Resistance to cerebral ischemic injury in UCP2 knockout mice: evidence for a role of UCP2 as a regulator of mitochondrial glutathione levels. J Neurochem 89:1283-1292.

Diano S, Matthews RT, Patrylo P, Yang L, Beal MF, Barnstable CJ, Horvath TL (2003) Uncoupling protein 2 prevents neuronal death including that occurring during seizures: a mechanism for preconditioning. Endocrinology 144:5014-5021.

Ding C, Wang P, Tian N (2011) Effect of general anesthetics on IOP in elevated IOP mouse model. Exp Eye Res 92:512-520.

Donadelli M, Dando I, Fiorini C, Palmieri M (2014) UCP2, a mitochondrial protein regulated at multiple levels. Cell Mol Life Sci 71:1171-1190.

Echtay KS, Winkler E, Frischmuth K, Klingenberg M (2001) Uncoupling proteins 2 and 3 are highly active $\mathrm{H}(+)$ transporters and highly nucleotide sensitive when activated by coenzyme Q (ubiquinone). Proc Natl Acad Sci U S A 98:1416-1421.

Ferreira SM, Lerner SF, Brunzini R, Reides CG, Evelson PA, Llesuy SF (2010) Time course changes of oxidative stress markers in a rat experimental glaucoma model. Invest Ophthalmol Vis Sci 51:4635-4640.

Fleury C, Neverova M, Collins S, Raimbault S, Champigny O, Levi-Meyrueis C, Bouillaud F, Seldin MF, Surwit RS, Ricquier D, Warden CH (1997) Uncoupling protein-2: a novel gene linked to obesity and hyperinsulinemia. Nat Genet 15:269-272.

Frank M, Duvezin-Caubet S, Koob S, Occhipinti A, Jagasia R, Petcherski A, Ruonala MO, Priault M, Salin B, Reichert AS (2012) Mitophagy is triggered by mild oxidative stress in a mitochondrial fission dependent manner. Biochim Biophys Acta 1823:2297-2310.

Ganat YM, Silbereis J, Cave C, Ngu H, Anderson GM, Ohkubo Y, Ment LR, Vaccarino FM (2006) Early postnatal astroglial cells produce multilineage precursors and neural stem cells in vivo. J Neurosci 26:8609-8621.

Garcia-Medina JJ, Garcia-Medina M, Garrido-Fernandez P, Galvan-Espinosa J, Garcia-Maturana C, Zanon-Moreno V, Pinazo-Duran MD (2015) A two-year follow-up of oral antioxidant supplementation in primary open-angle glaucoma: an open-label, randomized, controlled trial. Acta Ophthalmol 93:546-554.

Haines BA, Mehta SL, Pratt SM, Warden CH, Li PA (2010) Deletion of mitochondrial uncoupling protein-2 increases ischemic brain damage after transient focal ischemia by altering gene expression patterns and enhancing inflammatory cytokines. J Cereb Blood Flow Metab 30:18251833.

Haslip M, Dostanic I, Huang Y, Zhang Y, Russell KS, Jurczak MJ, Mannam P, Giordano F, Erzurum SC, Lee PJ (2015) Endothelial uncoupling protein 2 regulates mitophagy and pulmonary hypertension during intermittent hypoxia. Arterioscler Thromb Vasc Biol 35:1166-1178.

Ito YA, Di Polo A (2017) Mitochondrial dynamics, transport, and quality control: a bottleneck for retinal ganglion cell viability in optic neuropathies. Mitochondrion 36:186-192.

Izzotti A, Saccà SC, Cartiglia C, De Flora S (2003) Oxidative deoxyribonucleic acid damage in the eyes of glaucoma patients. Am J Med 114:638646.

Johansen T, Lamark T (2011) Selective autophagy mediated by autophagic adapter proteins. Autophagy 7:279-296.

Ju WK, Kim KY, Noh YH, Hoshijima M, Lukas TJ, Ellisman MH, Weinreb RN, Perkins GA (2015) Increased mitochondrial fission and volume density by blocking glutamate excitotoxicity protect glaucomatous optic nerve head astrocytes. Glia 63:736-753.

Kawasaki A, Otori Y, Barnstable CJ (2000) Müller cell protection of rat retinal ganglion cells from glutamate and nitric oxide neurotoxicity. Invest Ophthalmol Vis Sci 41:3444-3450.
Khawaja AP, Cooke Bailey JN, Kang JH, Allingham RR, Hauser MA, Brilliant M, Budenz DL, Christen WG, Fingert J, Gaasterland D, Gaasterland T, Kraft P, Lee RK, Lichter PR, Liu Y, Medeiros F, Moroi SE, Richards JE, Realini T, Ritch R, et al. (2016) Assessing the association of mitochondrial genetic variation with primary open-angle glaucoma using gene-set analyses. Invest Ophthalmol Vis Sci 57:5046-5052.

Kim I, Lemasters JJ (2011) Mitophagy selectively degrades individual damaged mitochondria after photoirradiation. Antioxid Redox Signal 14:1919-1928.

Kim I, Rodriguez-Enriquez S, Lemasters JJ (2007) Selective degradation of mitochondria by mitophagy. Arch Biochem Biophys 462:245-253.

Kimura A, Namekata K, Guo X, Noro T, Harada C, Harada T (2017) Targeting oxidative stress for treatment of glaucoma and optic neuritis. Oxid Med Cell Longev 2017:2817252.

Kong GY, Van Bergen NJ, Trounce IA, Crowston JG (2009) Mitochondrial dysfunction and glaucoma. J Glaucoma 18:93-100.

Korshunov SS, Skulachev VP, Starkov AA (1997) High protonic potential actuates a mechanism of production of reactive oxygen species in mitochondria. FEBS Lett 416:15-18.

Kwong JM, Quan A, Kyung H, Piri N, Caprioli J (2011) Quantitative analysis of retinal ganglion cell survival with Rbpms immunolabeling in animal models of optic neuropathies. Invest Ophthalmol Vis Sci 52:96949702 .

Lapp DW, Zhang SS, Barnstable CJ (2014) Stat3 mediates LIF-induced protection of astrocytes against toxic ROS by upregulating the UPC2 mRNA pool. Glia 62:159-170.

Lee S, Van Bergen NJ, Kong GY, Chrysostomou V, Waugh HS, O’Neill EC, Crowston JG, Trounce IA (2011) Mitochondrial dysfunction in glaucoma and emerging bioenergetic therapies. Exp Eye Res 93:204-212.

Lemasters JJ (2005) Selective mitochondrial autophagy, or mitophagy, as a targeted defense against oxidative stress, mitochondrial dysfunction, and aging. Rejuvenation Res 8:3-5.

Malone PE, Hernandez MR (2007) 4-Hydroxynonenal, a product of oxidative stress, leads to an antioxidant response in optic nerve head astrocytes. Exp Eye Res 84:444-454.

Masand R, Paulo E, Wu D, Wang Y, Swaney DL, Jimenez-Morales D, Krogan NJ, Wang B (2018) Proteome Imbalance of Mitochondrial Electron Transport Chain in Brown Adipocytes Leads to Metabolic Benefits. Cell Metab 27:616-629.e4.

Mattiasson G, Shamloo M, Gido G, Mathi K, Tomasevic G, Yi S, Warden CH, Castilho RF, Melcher T, Gonzalez-Zulueta M, Nikolich K, Wieloch T (2003) Uncoupling protein-2 prevents neuronal death and diminishes brain dysfunction after stroke and brain trauma. Nat Med 9:1062-1068.

Miwa S, St-Pierre J, Partridge L, Brand MD (2003) Superoxide and hydrogen peroxide production by Drosophila mitochondria. Free Radic Biol Med 35:938-948.

Moreno MC, Campanelli J, Sande P, Sánez DA, Keller Sarmiento MI, Rosenstein RE (2004) Retinal oxidative stress induced by high intraocular pressure. Free Radic Biol Med 37:803-812.

Mousa A, Kondkar AA, Al-Obeidan SA, Azad TA, Sultan T, Osman E, AbuAmero KK (2015) Association of total antioxidants level with glaucoma type and severity. Saudi Med J 36:671-677.

Murphy JL, Ratnaike TE, Shang E, Falkous G, Blakely EL, Alston CL, Taivassalo T, Haller RG, Taylor RW, Turnbull DM (2012) Cytochrome c oxidase-intermediate fibres: importance in understanding the pathogenesis and treatment of mitochondrial myopathy. Neuromuscul Disord 22: 690-698.

Nègre-Salvayre A, Hirtz C, Carrera G, Cazenave R, Troly M, Salvayre R, Pénicaud L, Casteilla L (1997) A role for uncoupling protein-2 as a regulator of mitochondrial hydrogen peroxide generation. FASEB J 11:809815.

Novak I, Kirkin V, McEwan DG, Zhang J, Wild P, Rozenknop A, Rogov V, Löhr F, Popovic D, Occhipinti A, Reichert AS, Terzic J, Dötsch V, Ney PA, Dikic I (2010) Nix is a selective autophagy receptor for mitochondrial clearance. EMBO Rep 11:45-51.

Pecqueur C, Alves-Guerra MC, Gelly C, Levi-Meyrueis C, Couplan E, Collins S, Ricquier D, Bouillaud F, Miroux B (2001) Uncoupling protein 2, in vivo distribution, induction upon oxidative stress, and evidence for translational regulation. J Biol Chem 276:8705-8712.

Perreten Lambert H, Zenger M, Azarias G, Chatton JY, Magistretti PJ, Lengacher S (2014) Control of mitochondrial $\mathrm{pH}$ by uncoupling protein 4 in astrocytes promotes neuronal survival. J Biol Chem 289:31014-31028. 
Piantadosi CA, Carraway MS, Babiker A, Suliman HB (2008) Heme oxygenase-1 regulates cardiac mitochondrial biogenesis via Nrf2mediated transcriptional control of nuclear respiratory factor-1. Circ Res 103:1232-1240.

Pinzon-Guzman C, Zhang SS, Barnstable CJ (2011) Specific protein kinase $\mathrm{C}$ isoforms are required for rod photoreceptor differentiation. J Neurosci 31:18606-18617.

Quigley HA (2011) Glaucoma. Lancet 377:1367-1377.

Resnikoff S, Keys TU (2012) Future trends in global blindness. Indian J Ophthalmol 60:387-395.

Richard D, Clavel S, Huang Q, Sanchis D, Ricquier D (2001) Uncoupling protein 2 in the brain: distribution and function. Biochem Soc Trans 29:812-817.

Robson-Doucette CA, Sultan S, Allister EM, Wikstrom JD, Koshkin V, Bhattacharjee A, Prentice KJ, Sereda SB, Shirihai OS, Wheeler MB (2011) Beta-cell uncoupling protein 2 regulates reactive oxygen species production, which influences both insulin and glucagon secretion. Diabetes 60:2710-2719.

Rodriguez AR, de Sevilla Müller LP, Brecha NC (2014) The RNA binding protein RBPMS is a selective marker of ganglion cells in the mammalian retina. J Comp Neurol 522:1411-1443.

Sandoval H, Thiagarajan P, Dasgupta SK, Schumacher A, Prchal JT, Chen M, Wang J (2008) Essential role for nix in autophagic maturation of erythroid cells. Nature 454:232-235.

Sappington RM, Carlson BJ, Crish SD, Calkins DJ (2010) The microbead occlusion model: a paradigm for induced ocular hypertension in rats and mice. Invest Ophthalmol Vis Sci 51:207-216.

Sarafian TA, Montes C, Imura T, Qi J, Coppola G, Geschwind DH, Sofroniew MV (2010) Disruption of astrocyte STAT3 signaling decreases mitochondrial function and increases oxidative stress in vitro. PLoS One 5:e9532.

Shen C, Chen L, Jiang L, Lai TY (2015) Neuroprotective effect of epigallocatechin-3-gallate in a mouse model of chronic glaucoma. Neurosci Lett 600:132-136.

Tanida I, Ueno T, Kominami E (2004) Human light chain 3/MAP1LC3B is cleaved at its carboxyl-terminal Met121 to expose Gly120 for lipidation and targeting to autophagosomal membranes. J Biol Chem 279: 47704-47710.

Tanihara H, Hangai M, Sawaguchi S, Abe H, Kageyama M, Nakazawa F, Shirasawa E, Honda Y (1997) Up-regulation of glial fibrillary acidic pro- tein in the retina of primate eyes with experimental glaucoma. Arch Ophthalmol 115:752-756.

Tewari S, Santos JM, Kowluru RA (2012) Damaged mitochondrial DNA replication system and the development of diabetic retinopathy. Antioxid Redox Signal 17:492-504.

Tham YC, Li X, Wong TY, Quigley HA, Aung T, Cheng CY (2014) Global prevalence of glaucoma and projections of glaucoma burden through 2040: a systematic review and meta-analysis. Ophthalmology 121: 2081-2090.

Uittenbogaard M, Chiaramello A (2014) Mitochondrial biogenesis: a therapeutic target for neurodevelopmental disorders and neurodegenerative diseases. Curr Pharm Des 20:5574-5593.

Valente AJ, Maddalena LA, Robb EL, Moradi F, Stuart JA (2017) A simple ImageJ macro tool for analyzing mitochondrial network morphology in mammalian cell culture. Acta Histochem 119:315-326.

Varela HJ, Hernandez MR (1997) Astrocyte responses in human optic nerve head with primary open-angle glaucoma. J Glaucoma 6:303-313.

Wang J, O'Sullivan ML, Mukherjee D, Puñal VM, Farsiu S, Kay JN (2017) Anatomy and spatial organization of Müller glia in mouse retina. J Comp Neurol 525:1759-1777.

Wei R, Stewart EA, Amoaku WM (2013) Suitability of endogenous reference genes for gene expression studies with human intraocular endothelial cells. BMC Res Notes 6:46.

Woldemussie E, Wijono M, Ruiz G (2004) Müller cell response to laserinduced increase in intraocular pressure in rats. Glia 47:109-119.

Wong-Riley M (1979) Changes in the visual system of monocularly sutured or enucleated cats demonstrable with cytochrome oxidase histochemistry. Brain Res 171:11-28.

Young P, Qiu L, Wang D, Zhao S, Gross J, Feng G (2008) Single-neuron labeling with inducible Cre-mediated knockout in transgenic mice. Nat Neurosci 11:721-728.

Zhang CY, Baffy G, Perret P, Krauss S, Peroni O, Grujic D, Hagen T, VidalPuig AJ, Boss O, Kim YB, Zheng XX, Wheeler MB, Shulman GI, Chan CB, Lowell BB (2001) Uncoupling protein-2 negatively regulates insulin secretion and is a major link between obesity, beta cell dysfunction, and type 2 diabetes. Cell 105:745-755.

Zhang Y, Riesterer C, Ayrall AM, Sablitzky F, Littlewood TD, Reth M (1996) Inducible site-directed recombination in mouse embryonic stem cells. Nucleic Acids Res 24:543-548. 